\title{
Vulnerabilidade das praias do Estado de Santa Catarina a eventos de erosão e inundação costeira: proposta metodológica baseada em um índice multicritério Vulnerability of Santa Catarina beaches to coastal erosion and flooding: a
methodological approach based on a multicriterial index
} Mirela Barros Serafim ${ }^{\text {ac }}$, Jarbas Bonetti ${ }^{\text {bd }}$

${ }^{a}$ Laboratório de Dinâmica Costeira, Universidade de São Paulo, baboratório de Oceanografia Costeira, Departamento de Geociências, Universidade Federal de Santa Catarina, Campus Universitário

cmirelabserafim@gmail.com, ${ }^{\mathrm{d}}$ jarbas.bonetti@ufsc.br

\begin{abstract}
Resumo
A zona costeira do Estado de Santa Catarina (SC) encontra-se submetida a condições oceanográficas e meteorológicas transicionais. A passagem regular de frentes frias e a incidência de ventos de relativa intensidade condicionam a ocorrência de marés de tempestade (ondas extremas associadas a marés meteorológicas de grande amplitude), as quais podem resultar em eventos de inundação e erosão praial, causando danos materiais aos assentamentos costeiros. As praias arenosas são os ambientes predominantes ao longo da linha de costa de SC e possuem elevado valor social e econômico devido à variedade de serviços prestados e à alta densidade demográfica dos setores adjacentes. Desta forma, o estudo da vulnerabilidade costeira torna-se de grande relevância para fins de ordenamento da ocupação e estabelecimento de planos de mitigação para essas áreas. Este trabalho apresenta uma proposta metodológica para o mapeamento da vulnerabilidade costeira de SC frente a eventos extremos de ondas e marés a partir da elaboração de um índice multicritério aplicado através de um Sistema de Informações Geográficas. A vulnerabilidade foi obtida pela integração de dois submodelos: suscetibilidade (composto por variáveis do meio físico) e capacidade adaptativa (composto por variáveis socioeconômicas). Os maiores valores de vulnerabilidade foram encontrados em trechos centrais dos setores Norte e Centro-Norte e em segmentos isolados no setor Centro. Os fatores socioeconômicos apresentaram alta relevância para os grandes balneários do setor Centro-Norte (como os dos municípios de Balneário Camboriú, Itapema e Navegantes) onde, no geral, os graus de vulnerabilidade foram inferiores aos de suscetibilidade devido à alta capacidade adaptativa local. Por outro lado, os setores Sul e Centro-Sul, embora tenham apresentado capacidade adaptativa relativamente baixa, foram os menos vulneráveis, indicando que o cenário de baixa suscetibilidade foi mais condicionante nestas áreas.
\end{abstract}

Palavras-chave: suscetibilidade costeira; capacidade adaptativa; marés de tempestade; análise espacial.

\begin{abstract}
The coastal zone of Santa Catarina State (SC) lies under transitional oceanographic and meteorological conditions. The regular passage of cold fronts and the incidence of winds with relative high intensity lead to the occurrence of storm surges, which can result in episodes of coastal flooding and beach erosion. Those, by their turn, may induce property damage to the coastal settlements. Sandy beaches are the dominant environments along Santa Catarina's coastline and have high social and economic value due to the variety of activities undertaken and to the high nearby population density. Thus, the study of coastal vulnerability is of great relevance for urban planning purposes and mitigation efforts in these areas. This study proposes a methodological framework for the mapping of Santa Catarina's coastal vulnerability to extreme events of waves and tides based on the development of a multicriteria index through a Geographical Information System. The vulnerability was obtained from the integration of two sub-models: susceptibility (consisting of environmental variables) and adaptive capacity (composed by socioeconomic variables). The highest values of vulnerability were found in central portions of the North and Central-North sectors and in segments at the north of the Central sector. The socioeconomic descriptors had great relevance over large settlements in Central-North sector (such as the cities of Balneário Camboriu, Itapema and Navegantes) where the vulnerability was lower than susceptibility in most cases due to their high adaptive capacity. On the other hand, the South and Central-South sectors showed relatively low levels of adaptive capacity, but even so they were identified as the least vulnerable, indicating that the scenario of low susceptibility is a determining factor in these areas.
\end{abstract}

Keywords: coastal susceptibility; adaptive capacity; storm surges; spatial analysis. 


\section{Introdução}

Entre outras delimitações possíveis, a zona costeira pode ser considerada como sendo composta pelas áreas da plataforma continental interna e da costa emersa em que a dinâmica marinha determina os processos morfodinâmicos atuantes (CEPAL 2012). Os diferentes ambientes costeiros presentes nessa estreita faixa respondem de forma distinta à transferência de energia a partir do sistema oceânico. Entre eles, as praias se destacam como sistemas transicionais altamente dinâmicos e sensíveis a flutuações locais de energia (Hoefel 1998), sendo amplamente retrabalhadas durante a ação de eventos extremos.

No Estado de Santa Catarina, em 2010, 28\% da população estadual habitava nos municípios definidos administrativamente como sendo costeiros, segundo os dados censitários do Instituto Brasileiro de Geografia e Estatística (IBGE 2010a). Esta parcela, correspondente a 1.942.473 milhão de pessoas, representa o contingente populacional mais propício a ser afetado em episódios de erosão e inundação costeira.

A identificação regional dos setores costeiros mais vulneráveis pode auxiliar na definição de prioridades de gestão (Abuodha \& Woodroffe 2010a), colaborando com o poder público no ordenamento da ocupação e estabelecimento de planos de mitigação para os efeitos adversos desses eventos sobre a população, bens e serviços prestados. Tais produtos podem dar suporte a estudos de maior resolução espacial, essenciais quando se pretende implementar medidas concretas de proteção à costa.

O Estado de Santa Catarina encontra-se submetido a condições oceanográficas e meteorológicas transicionais e de forte dinâmica. A passagem de frentes frias e a atuação de ciclones extratropicais acontecem regularmente e tais sistemas influenciam a ocorrência de marés meteorológicas e ondas de tempestade, podendo acarretar severos danos materiais aos assentamentos costeiros - principalmente quando associados a marés astronômicas de sizígia.

Entre os anos de 1997 e 2010, Rudorff et al. (2014) identificaram a ocorrência de 46 episódios de maré de tempestade no litoral catarinense. Segundo os autores, um único evento relacionado à ocorrência de um ciclone extratropical - a tempestade de maio de 2001 afetou 11 municípios no estado, representando uma perda econômica avaliada em mais de 11 milhões de reais. Segundo Krueger (2011), entre os meses de abril e maio de 2010, uma sequência de "ressacas" atingiu o litoral catarinense, danificando 70 casas e deixando 1.803 pessoas afetadas e 21 desalojadas somente no município de Florianópolis.

Neste contexto, o presente trabalho tem como objetivo avaliar, de forma integrada, a vulnerabilidade das praias distribuídas ao longo da linha de costa do Estado de Santa Catarina frente à atuação de ondas de tempestade e marés meteorológicas. A estratégia utilizada consiste na aplicação de um índice multicritério associado à análise espacial em ambiente de Sistema de Informações Geográficas (SIG).

$\mathrm{O}$ índice de vulnerabilidade adotado foi adaptado do Coastal Vulnerability Index (CVI) proposto por Gornitz (1991). O CVI é um índice multicritério que permite a avaliação da resposta física relativa de setores da linha de costa frente a perigos costeiros. É determinado através da inserção de descritores qualitativos e quantitativos em uma fórmula matemática, nela expressos após terem sido hierarquizados individualmente em graus de vulnerabilidade.

Índices de vulnerabilidade costeira similares foram posteriormente aplicados em muitos setores da costa dos EUA pela United States Geological Search (USGS), incluindo as costas Atlântica, Pacífica e do Golfo do México (Hammar-Klose \& Thieler 2001, Hammar-Klose et al. 2003). Suas características e uma ampla lista de aplicações e adaptações do método, que visaram contemplar as especificidades regionais, foram discutidas por Nguyen et al. (2016), podendo-se destacar: Torresan et al. (2008), Abuodha \& Woodroffe (2010b), Mclaughlin \& Cooper (2010), Bonetti et al. (2013) e Bonetti et al. (2015).

A adaptação aqui proposta considerou os principais condicionantes à vulnerabilidade costeira pela ação marinha em SC, bem como a disponibilidade de dados a nível regional. Desta forma, variáveis originalmente propostas por Gornitz (1991) na construção do CVI foram aqui desconsideradas por terem baixa variabilidade regional (tipo de rocha, taxa de subida do nível do mar), enquanto outras consideradas de maior relevância para a área de estudo foram incluídas (largura da praia e discriminação das marés em suas componentes astronômica e meteorológica). Apesar de relevante, a altitude do pós-praia não foi incluída pela indisponibilidade deste dado em escala estadual no momento de realização da pesquisa. Conforme será detalhado na metodologia, a forma de tratamento dos dados de onda também difere da proposta original, tendo-se aqui priorizado a exposição da costa em relação às direções predominantes de fluxo de energia e não apenas sua altura. Visando ampliar a aplicabilidade deste índice, é apresentada uma proposta metodológica para a incorporação de variáveis socioeconômicas, não consideradas no CVI original Gornitz (1991). Por fim, priorizou-se a subdivisão das variáveis em classes de suscetibilidade, capacidade adaptativa e vulnerabilidade com base em um método estatístico, buscando-se assim minimizar a subjetividade da proposta original.

Visando facilitar a interpretação e posterior integração dos dados a estudos de planejamento costeiro no estado, os resultados foram associados aos setores delimitados pelo Plano Estadual de Gerenciamento Costeiro de Santa Catarina (GERCO/SC), definidos em Santa Catarina (2006). 


\section{Conceituação adotada na pesquisa}

Para os fins deste estudo, compreende-se perigo costeiro como o fenômeno ou processo natural com potencial para causar danos à população costeira (IPCC 2014). Tem-se como exemplos os fenômenos de marés meteorológicas e ondas de tempestade, aqui representados, que acarretam processos erosivos e inundacionais.

Eventuais danos na zona costeira irão se manifestar segundo uma maior ou menor propensão à alteração da condição de equilíbrio dinâmico de um setor em função das características de seu meio físico, compreendida como suscetibilidade (Muler \& Bonetti 2014).

Outro componente de relevância na avaliação de impactos decorrentes de perigos costeiros é a capacidade adaptativa, relacionada à existência de uma maior habilidade de uma comunidade em enfrentar, resistir e se recuperar após ter sido afetada por um evento extremo, identificada através de fatores sociais e econômicos (UNISDR 2009).

A vulnerabilidade, por sua vez, vincula-se à ideia ampla de se estar propenso a sofrer danos ou perdas devido à ação de um perigo. Aqui ela é entendida como resultante da associação entre suscetibilidade e capacidade adaptativa (Nguyen et al. 2016, Bonetti \& Woodroffe 2017).

Desta forma, com base no referencial aqui adotado, uma baixa vulnerabilidade reflete uma maior capacidade de uma área em se antecipar, enfrentar, resistir e se recuperar do impacto produzido por um agente de dada magnitude, considerando-se os elementos de seus meios físico e socioeconômico.

\section{Área de estudo}

A área de estudo compreende a zona costeira do Estado de Santa Catarina, localizada na Região Sul do Brasil (Fig.1) - delimitada pelos paralelos 2557'41" e $29^{\circ} 23^{\prime} 55^{\prime \prime}$ e distribuída aproximadamente ao longo dos eixos SW-NE e S-N (IBGE 2000).

A costa oceânica do estado é representada por 564 $\mathrm{km}$ de linha de costa, ou $1.874 \mathrm{~km}$ quando contabilizadas suas baías e ilhas mais expressivas (FATMA 2010). De acordo com Klein et al. (2016), no estado podem ser identificadas 246 praias arenosas, que ocupam $60 \%$ da linha de costa.

A Região Sul do Brasil é caracterizada pela transição de eventos meteoceanográficos. Sobre ela ocorre o encontro entre as massas Tropical Atlântica (quente e úmida) e Polar Atlântica (fria e menos úmida), dando origem à Frente Polar Atlântica, responsável por bruscas mudanças nas condições de tempo em qualquer época do ano (Monteiro \& Furtado 1995). Sobretudo entre o outono e o inverno, frentes frias avançam pelo sul do Brasil geralmente associadas a ciclones extratropicais (Ayoade 1996), outro sistema que se caracteriza pela expressiva transferência de energia da atmosfera para o oceano.

Dados de reanálise do National Center for Environmental Prediction - National Center for Atmospheric Research (NCEP/NCAR) para os anos de
1990 a 1999 indicaram uma média mensal de 3 a 4 frentes frias atingindo o litoral catarinense (Rodrigues et al. 2004). A passagem destas influencia a ocorrência de marés meteorológicas e ondas de tempestade, ocasionando episódios de inundação costeira e erosão praial que podem acarretar danos materiais principalmente quando associadas a marés astronômicas de sizígia. Trucollo (1998) constatou que os eventos meteorológicos podem elevar o nível do mar em até $1 \mathrm{~m}$ acima da maré astronômica e ocorrer na frequência de 10 dias.

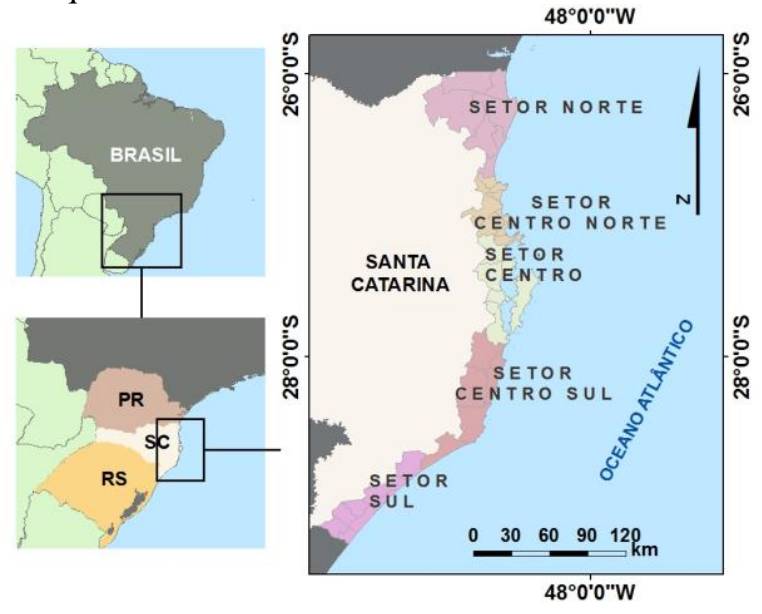

Figura 1: Localização da área de estudo.

Geomorfologicamente, as planícies costeiras são o domínio predominante ao longo do litoral do estado (Horn Filho \& Diehl 2004). Em seus limites oceânicos se estabelecem praias de extensão variada que se alternam com promontórios, ocorrendo uma extensa plataforma continental no substrato oceânico adjacente (Klein et al. 2016).

Diversos estudos relacionados à análise da vulnerabilidade e suscetibilidade das praias de Santa Catarina já foram desenvolvidos em diferentes escalas nos últimos 10 anos.

Mazzer (2007) analisou a vulnerabilidade à erosão do sudeste da Ilha de Santa Catarina através da identificação de unidades homogêneas representadas por células costeiras. Rudorff \& Bonetti (2010) aplicaram o método dos geoindicadores no reconhecimento do estado erosional e inferência da suscetibilidade de segmentos da Ilha de Santa Catarina. Mussi (2011) avaliou a sensibilidade (considerada sinônimo de suscetibilidade) e os riscos socioeconômicos da zona costeira da Ilha de Santa Catarina frente à elevação média do oceano e às ondas de tempestade, tendo a mesma abordagem metodológica sido posteriormente aplicada por Pavan (2012) e Scolaro (2013) nos litorais Centro-Sul e Centro-Norte do estado, respectivamente.

Para algumas praias da Ilha de Santa Catarina, Muler \& Bonetti (2014) propuseram uma abordagem integrada de avaliação da vulnerabilidade à ação de marés de tempestade a partir da identificação do grau de exposição às ondas incidentes dos setores com infraestrutura urbana localizada próximo à linha de costa. 
Um dos problemas relacionados à aplicação de índices de vulnerabilidade é a pouca comparabilidade entre pesquisas desenvolvidas por diferentes autores e em diferentes escalas (Bonetti \& Woodroffe 2017). Assim, apesar do bom volume de estudos pretéritos de caráter local, ainda não se dispõe de uma avaliação da vulnerabilidade na escala do Estado de Santa Catarina. O presente trabalho se propõe a preencher essa lacuna através de uma análise integrada para o estado como um todo, permitindo a efetiva comparabilidade entre os diferentes trechos costeiros que o compõe. Complementarmente, é dado destaque à componente humana através da determinação da capacidade adaptativa das populações costeiras, aspecto não contemplado pelos autores anteriormente citados.

\section{Materiais e métodos}

Na presente pesquisa foi desenvolvido e aplicado um índice semelhante ao originalmente proposto por Gornitz (1991), tendo sido selecionadas oito variáveis consideradas representativas para a área de estudo. A figura 2 apresenta a relação entre estas, e suas características e aproximações para espacialização são descritas a seguir.

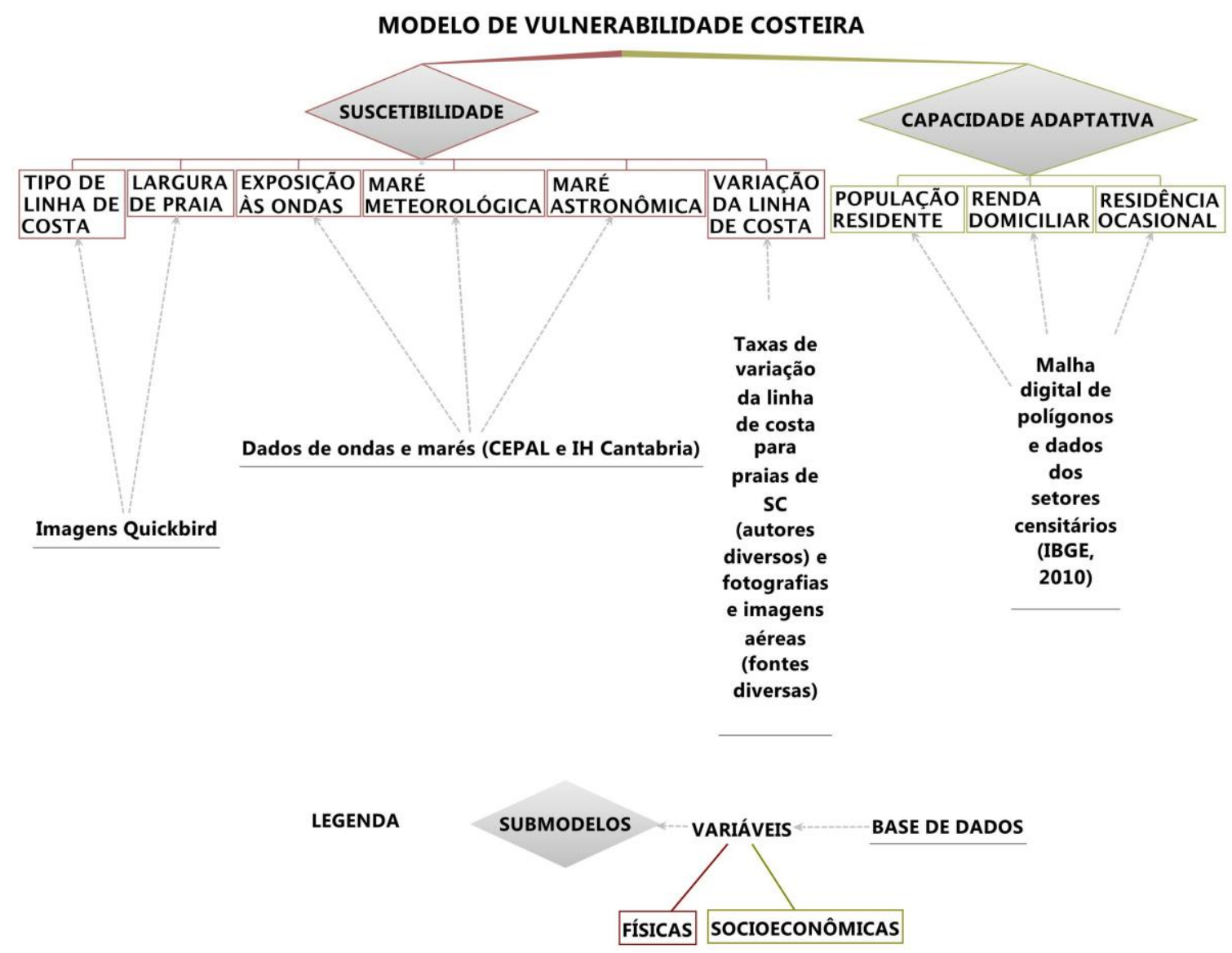

Figura 2: Fluxograma de desenvolvimento do modelo de vulnerabilidade costeira.

\section{Tipo de linha de costa}

Segundo Gornitz \& White (1992), os tipos de linha de costa (características do pós-praia relacionadas sobretudo aos ambientes naturais ou alterações antrópicas que ali ocorrem) que apresentam maiores riscos são os que possuem maior mobilidade e instabilidade, sustentados por materiais inconsolidados. A combinação entre os fatores condiciona diferentes graus de resiliência ambiental ao longo da costa - base para a determinação das classes de suscetibilidade.

A digitalização da linha de costa foi realizada através do editor do ArcGIS 9.3. A linha de costa foi segmentada a cada mudança de classe, sendo elas: vegetação costeira, praia, estrutura artificial, costão rochoso e desembocadura estuarina ou lagunar. Para as classes vegetação costeira, costão rochoso e estrutura artificial foi adotado o contato entre as áreas emersas e o oceano. As desembocaduras estuarinas e lagunares foram definidas a partir da união entre pontos localizados em suas margens opostas. Para as praias seguiu-se a interface entre areia seca e úmida, que será discutida adiante. Foram utilizadas imagens do satélite Quickbird dos anos de 2002 a 2010 como base geográfica, tendo-se utilizado preferencialmente a imagem mais recente e de boa qualidade disponível.

As imagens foram acessadas do servidor da empresa DigitalGlobe através da extensão Image Connect compatível com o software ArcGIS 9.3 e são compostas por três espectrais com resolução espacial de 2,4 m (EURIMAGE 2001). 


\section{Largura de praia}

Em sistemas praiais mais largos, a água percorre uma maior distância até o setor do pós-praia, favorecendo a dissipação da energia e, consequentemente, conferindo uma maior propensão à estabilidade. Logo, maiores larguras de praia podem ser associadas à baixa suscetibilidade.

A largura de praia foi medida através da ferramenta Measure do ArcGIS 9.3, tendo como base as imagens Quickbird anteriormente descritas.

A medição foi igualmente feita da interface entre areia seca e úmida até a base da duna frontal, quando presente, ou outra barreira física abrupta. A referida interface pôde ser facilmente delimitada nas imagens pela mudança de coloração decorrente dos diferentes padrões de reflexão da luz solar pelo sedimento e sua representatividade será discutida no item "Variação da linha de costa" (Leatherman 2003, Boak \& Turner 2005). A largura de praia foi medida em 302 pontos distanciados aproximadamente a cada $2 \mathrm{~km}$.

Devido à ausência de informações relativas ao horário de aquisição das imagens de satélite não foi possível realizar uma estimativa do erro induzido nessas medidas pela posição da maré. Todavia, dado o domínio de uma condição de micro-marés em todo o estado, considerou-se que os resultados obtidos ainda assim seriam representativos. De todo modo, a fim de minimizar eventuais discrepâncias, foram utilizados valores médios obtidos a partir de múltiplas medidas em cada ponto utilizando imagens adquiridas em datas distintas, idealmente três, dependendo da disponibilidade do acervo consultado.

\section{Maré meteorológica e astronômica}

A maré influencia tanto a inundação quanto a erosão costeira. Grandes amplitudes elevam o nível de base das ondas e geram correntes de maré mais fortes, capazes de erodir a costa e transportar os sedimentos (Gornitz et al. 1991). Assim, maiores amplitudes de maré potencializam um maior avanço do mar sobre a zona costeira, colaborando para o aumento da suscetibilidade.

Em estudos de vulnerabilidade costuma-se trabalhar com o pior cenário ambiental. Desta forma, valores extremos de amplitude de marés meteorológicas e astronômicas foram extraídos de dados provenientes do projeto Estudio regional de los efectos del cambio climático en la costa de América Latina y el Caribe, desenvolvido pela CEPAL em parceria com o Instituto de Hidráulica Ambiental da Universidade de Cantábria (IH Cantabria).

Através do visualizador web do projeto (http://www.c3a.ihcantabria.com/) foram obtidos, para onze pontos distribuídos ao longo da costa catarinense, valores extremos de marés meteorológicas com tempos de retorno (Tr) de 50 anos, bem como valores de maré astronômica referentes ao quantil 0,90 anual. Esses valores foram, em ambiente SIG, rebatidos para onze segmentos ao longo da linha de costa.

\section{Exposição às ondas}

Maiores alturas e fluxos de energia de onda potencializam um maior avanço do mar sobre a costa, induzindo um cenário de maior suscetibilidade.

A análise da variável exposição às ondas se deu com base na determinação do ângulo de exposição da linha de costa às ondas, na altura significativa de onda (Hs) e na direção do fluxo médio de energia de onda (dirFE). A relação entre as variáveis é apresentada na tabela 1.

A orientação da linha de costa foi obtida para segmentos de $2 \mathrm{~km}$ de extensão através da ferramenta Find Polyline Angle (Zazula 2005), compatível com o ArcGIS 9.3. O uso desta permitiu a adição de um campo denominado GeoAngle (ângulo de rotação do azimute do norte geográfico) à tabela de atributos do arquivo digital de linha de costa. O ângulo geográfico considera a direção norte equivalente a $0^{\circ}$, leste a $90^{\circ}$, sul a $180^{\circ}$ e oeste a $270^{\circ}$. Com base no processo de refração, pôde-se obter o ângulo de exposição do segmento às ondas, somando-se $90^{\circ}$ ao valor do GeoAngle - a normal da orientação.

Tabela 1: Matriz para determinação da exposição à onda.

\begin{tabular}{|c|c|c|c|c|c|c|c|}
\hline ID & Descritor & Fonte & $\begin{array}{l}1 \text { (Muito } \\
\text { baixo) }\end{array}$ & 2 (Baixo) & 3 (Médio) & 4 (Alto) & $\begin{array}{c}5 \text { (Muito } \\
\text { alto) }\end{array}$ \\
\hline $\mathrm{a}$ & $\begin{array}{c}\text { Direção do Fluxo de } \\
\text { Energia }\end{array}$ & $\begin{array}{l}\text { Find Polilyne Angle; Visualizador web } \\
\text { do projeto Estudio regional de los } \\
\text { efectos del cambio climático em la costa } \\
\text { de America Latina y el Caribe }\end{array}$ & Outro & $\begin{array}{l}N\left(0^{\circ}-22,4^{\circ} \mathrm{e}\right. \\
\left.337,5^{\circ}-359,9^{\circ}\right)\end{array}$ & $\begin{array}{l}\mathrm{NE}\left(22,5^{\circ}\right. \\
\left.-67,4^{\circ}\right)\end{array}$ & $\begin{array}{c}\mathrm{E}\left(67,5^{\circ}-112,4^{\circ}\right) \text { e } S \\
\left(157,5^{\circ}-202,4^{\circ}\right)\end{array}$ & $\begin{array}{l}\operatorname{SE}\left(112,5^{\circ}\right. \\
\left.-157,4^{\circ}\right)\end{array}$ \\
\hline $\mathrm{b}$ & $\begin{array}{l}\text { Altura de onda } \\
\text { (período de retorno de } \\
50 \text { anos) }(\mathrm{m})\end{array}$ & $\begin{array}{c}\text { Visualizador web do projeto Estudio } \\
\text { regional de los efectos del cambio } \\
\text { climático em la costa de America Latina } \\
\text { y el Caribe }\end{array}$ & $5,87-6,4$ & $6,41-6,53$ & $\begin{array}{l}6,54- \\
7,06\end{array}$ & $7,07-7,13$ & $7,14-7,61$ \\
\hline $\mathrm{x}^{*}$ & $\begin{array}{c}\text { Exposição do } \\
\text { segmento à onda }\end{array}$ & - & $1,00-3,00$ & $3,01-3,66$ & $\begin{array}{c}3,67- \\
4,33\end{array}$ & $4,34-4,66$ & $4,67-5,00$ \\
\hline
\end{tabular}


Optou-se pela utilização de valores já processados de altura significativa de onda (Hs) e de direção do fluxo médio de energia de onda (dirFE). Os valores obtidos para estas variáveis fazem parte da reanálise Global Ocean Waves (GOW) desenvolvida pelo IH Cantabria e estão disponíveis para os mesmos onze pontos da linha de costa de Santa Catarina utilizados para a extração dos dados de marés.

Entre os resultados da reanálise GOW, têm-se: parâmetros estatísticos de onda de resolução temporal horária e espacial de $0,5^{\circ}$ e espectros de energia com resolução temporal de 3 horas e espacial de $1^{\circ}$ (CEPAL 2011).

Do visualizador web do projeto, foram extraídos valores extremos de onda referentes à altura significativa máxima mensal com período de retorno (Tr) de 50 anos. Os valores expressam o 1/3 das maiores ondas em seu valor máximo mensal, refletindo as condições mais severas de onda por mês (CEPAL 2011).

O fluxo de energia de onda representa a taxa de transferência de energia que é transmitida na direção de propagação das ondas através de um plano vertical perpendicular ao avanço da direção de onda e estendido por toda a profundidade (USACE 2002). Assumiu-se que quanto maior o ângulo entre a direção de exposição do segmento e a direção do fluxo médio de energia (sudeste, ao longo de toda a costa catarinense), menor o grau de suscetibilidade. Desta forma, as direções de propagação nordeste e norte foram classificadas em suscetibilidade média e baixa, respectivamente. Os segmentos expostos às direções de propagação de onda de oeste, sudoeste e noroeste foram considerados como suscetibilidade muito baixa, uma vez que a linha de costa do estado encontra-se abrigada a fluxos de energia destas direções.

Os valores de $\mathrm{Hs} \mathrm{Tr}-50$ foram hierarquizados em quintis de suscetibilidade, considerando que maiores valores de altura de onda acarretam cenários de maior suscetibilidade costeira.

A suscetibilidade para a variável exposição às ondas foi obtida a partir da Equação 1:

$$
\mathrm{x}=(2 \mathrm{a}+\mathrm{b}) / 3
$$

onde $\mathrm{x}=$ exposição às ondas, $\mathrm{a}=$ grau de suscetibilidade da dirFE e $b=$ grau de suscetibilidade da Hs Tr-50.

Julgou-se a exposição à direção do fluxo médio de energia de onda (peso 2) mais relevante para a análise de suscetibilidade praial do que a altura significativa de onda (peso 1). A atribuição dos pesos considerou que uma praia que recebe um maior fluxo de energia é mais suscetível que outra com alto valor de Hs Tr-50, considerando que este geralmente representa episódios ocasionais.

\section{Taxa de variação da linha de costa}

Variações na posição da linha de costa podem ocorrer em escala de longo prazo, ocasionadas pela variação do nível médio do mar, de médio prazo, por exemplo devido à migração de uma desembocadura, ou de curto prazo, como em episódios de tempestades.

Independentemente da escala da variação, esta pode representar perigo às populações situadas em suas proximidades. Maiores taxas de retrogradação da linha de costa indicam um maior avanço do mar sobre a orla, resultando em um cenário de maior suscetibilidade.

Nesta pesquisa foram compiladas taxas de variação da linha de costa de estudos pretéritos, apresentadas na tabela 2, calculadas por meio do Digital Shoreline Analysis System (DSAS), extensão desenvolvida pelo United States Geological Survey (Thieler et al. 2009). Note-se que todas as taxas obtidas pelos autores citados cobrem intervalos superiores a 50 anos, tendo a linha de costa mais antiga disponível sido utilizada como linha de base nestes estudos. Alguns desses autores incluíram o Erro Quadrático Médio (RMS, na sigla em Inglês) da digitalização de cada imagem na ponderação do cálculo da taxa de variação da linha de costa, enquanto outros atribuíram maior incerteza às fotos mais antigas.

As taxas referentes ao arco praial Praia Grande - Ervino (município de São Francisco do Sul) e ao trecho da praia de Balneário Rincão foram calculadas no âmbito deste trabalho. Para tanto, foram utilizadas fotografias de levantamentos aerofotogramétricos dos anos 1957, 1978, 1995 e imagens aéreas de 2011 do sensor orbital Quickbird (tabela 3) - obtidas através do software Google Earth Pro ${ }^{\mathrm{TM}}$ com resolução de 4800 x 3312 pixels.

As fotografias e imagens aéreas foram georreferenciadas em ambiente SIG através da ferramenta georreferencing. A base cartográfica foi composta por imagens Quickbird acessadas pelo Image Connect, para o Balneário Rincão, e pela extensão BingMaps para a praia de São Francisco do Sul.

Esta base foi utilizada na seleção dos pontos de controle para a correção geométrica de cada imagem e fotografia aérea georreferenciada. Foram identificados 15 pontos, buscando-se uma boa distribuição espacial entre eles e a minimização do RMS.

O RMS foi multiplicado por uma constante tabelada $(1,7308)$ a fim de se obter um nível de confiança de 95\% em relação à posição verdadeira dos pontos na base cartográfica (FGDC-STD 1998).

Como no caso da delimitação da linha de costa recente e cálculo da largura de praia, novamente a linha de preamar foi adotada como critério de delimitação das linhas de costa históricas.

O uso deste indicador foi criticado por Muehe \& Klumb-Oliveira (2014), que argumentam que o estado morfodinâmico da praia (sobretudo devido às variações de declividade), pode eventualmente induzir deslocamentos horizontais da linha de costa com ordem de grandeza superior ao seu deslocamento histórico. De fato, uma série de aspectos atuantes no momento de aquisição da imagem e de difícil correção, tais como a condição da maré, intensidade e direção 
Tabela 2: Taxas de variação da linha de costa obtidas para Santa Catarina.

\begin{tabular}{|l|c|c|c|}
\hline Praia (Município) & Datas das imagens/fotografias & Taxa (m/ano) & Referência \\
\hline Praia Grande - Ervino (São Francisco do Sul) & $1957,1978,1995,2011$ & $-0,35$ \\
\hline Armação de Itapocorói (Piçarras) & $1957,1978,1995,2005$ & $-0,13$ & Elaboração própria \\
\hline Ingleses (Florianópolis) & $1957,1978,1994,2002,2007,2009$ & $-0,73$ \\
\hline Moçambique - Barra da Lagoa (Florianópolis) & $1957,1978,1994,2002,2007,2010$ & $-0,35$ & Muler (2012) \\
\hline Armação (Florianópolis) & $1957,1978,1994,2002,2007,2011$ & $-0,18$ & Muler (2012) \\
\hline Itapirubá (entre Imbituba/Laguna) & $1938,1957,1978,1995,2009$ & $-0,25$ & $-0,3$ \\
\hline Rincão (Balneário Rincão) & $1957,1978,1995,2011$ & Siler (2012) \\
\hline
\end{tabular}

Tabela 3: Imagens e fotografias aéreas utilizadas para o cálculo da taxa de variação da linha de costa.

\begin{tabular}{|c|c|c|}
\hline Data & Escala/Resolução & Entidade/Eempresa responsável \\
\hline $\mathbf{1 9 5 7}$ & $1: 25.000 / 600 \mathrm{dpi}$ & $\begin{array}{c}\text { Secretaria de Planejamento do } \\
\text { Estado }\end{array}$ \\
\hline $\mathbf{1 9 7 8}$ & $1: 25.000 / 600 \mathrm{dpi}$ & $\begin{array}{c}\text { Departamento Nacional de } \\
\text { Produção Mineral }\end{array}$ \\
\hline $\mathbf{1 9 9 5}$ & $1: 12.500 / 600 \mathrm{dpi}$ & $\begin{array}{c}\text { Superintendência do Patrimônio } \\
\text { da União no Estado de Santa } \\
\text { Catarina }\end{array}$ \\
\hline $\mathbf{2 0 1 1}$ & $\begin{array}{c}-/ 4800 \times 3312 \\
\text { pixels }\end{array}$ & Google Earth Pro \\
\hline \multicolumn{2}{|c|}{ Todavia considerando a dificuldade em se }
\end{tabular}

identificar o limite do pós-praia ao longo da costa de Santa Catarina, dada a presença de vários trechos com a vegetação da duna frontal descaracterizada pela ação antrópica, o limite da face ativa da praia foi adotado nesta pesquisa por ser o indicador mais discernível e constante nas imagens para o estado como um todo. Além disso, uma vez que ocorre o predomínio de um regime de micro-marés de fase semi-diurna em todo o estado, condição considerada ideal para aplicação do indicador limite areia seca/úmida (Crowell et al. 1991), considerou-se que os eventuais erros de interpretação associados à sua adoção na escala desta pesquisa podem ser considerados negligenciáveis.

Após o georreferenciamento, a taxa de variação foi calculada através do DSAS, optando-se pelo método Weighted Linear Regression (WLR). Este considera todas as linhas de costa relativas aos diferentes anos analisados (1957, 1978, 1995 e 2011) e calcula a distância destas a uma linha definida pelo usuário (no caso desta pesquisa, a linha de costa mais antiga), além de atribuir menor peso à linha de costa de maior incerteza. Como valor de incerteza, utilizou-se o RMS obtido a partir do georreferenciamento das fotos e imagens de satélite.

No trecho do Balneário Rincão foram traçados 60 transectos, distanciados a cada $150 \mathrm{~m}$. Para o arco Praia Grande - Ervino, a distância estabelecida foi de $250 \mathrm{~m}$, resultando no total de 104 transectos.

Com exceção da taxa obtida por Freitas (2008) para a praia Armação do Itapocorói, todas as demais taxas espacializadas ao longo da linha de costa foram calculadas pelo WLR. Freitas (2008) optou pelo método End Point Rate (EPR) do DSAS. Diferentemente dos demais, esse autor também subdividiu a praia em três setores e calculou taxas de variação de linha de costa por segmento praial. A taxa utilizada para fins deste trabalho foi a do pior cenário encontrado, cuja variação média foi de -0,45 m/ano.
Silva (2010) não chegou a calcular a taxa de variação para a praia de Itapirubá. No entanto, a partir das linhas de costa digitalizadas pela autora e disponibilizadas na forma de imagem, a taxa de variação foi aqui calculada pelo método WLR. Foram atribuídas arbitrariamente maiores incertezas para as linhas de costa mais antigas: 5 m (1938), 4 m (1957), 3 m (1978), 2 m (1995) e $1 \mathrm{~m}$ (2009).

\section{Variáveis socioeconômicas}

Os dados socioeconômicos foram obtidos a partir de tabelas disponibilizadas pelo censo do Instituto Brasileiro de Geografia e Estatística (IBGE), realizado na data de referência de 31 de julho de 2010 (IBGE 2011). A malha geométrica de coleta de dados é representada pelos setores censitários - o menor nível setorial de coleta de dados, equivalente à área percorrida por um único recenseador (IBGE 2011). Foram consideradas representativas as seguintes variáveis:

População residente - Segundo McLaughlin et al. (2002), a população residente pode ser vista de duas maneiras em relação à sua participação na vulnerabilidade costeira: do ponto de vista econômico e do ponto de vista de potencial erosivo e inundável. Para os autores, um grande número de residentes resulta em um cenário de alta vulnerabilidade, uma vez que expõe um maior número de construções que podem refletir em gasto econômico. Tal gasto poderia se dar através da necessidade de sua eventual reconstrução ou ainda a construção de novas estruturas de proteção ao impacto da água do mar. Um número elevado de residentes também indica a probabilidade de um maior número de pessoas ser afetado em eventos de inundação e erosão (McLaughlin et al. 2002). A partir destas considerações, determinou-se que quanto maior o número de residentes do setor censitário, maior sua vulnerabilidade e, portanto, menor a sua capacidade adaptativa.

Renda domiciliar - A renda está relacionada ao padrão construtivo das casas e à possibilidade de construção de estruturas de proteção e de reconstrução das edificações danificadas. Portanto, quanto maior o rendimento domiciliar do setor censitário, maior será a sua capacidade adaptativa.

Residência ocasional - É um indicativo de segunda moradia. Na ocorrência de danos no domicílio sobre a linha de costa, seus moradores têm outro local para onde se deslocar. Também indica uma maior probabilidade de os moradores não estarem presentes 
durante a ação de eventos de tempestade na costa, não sendo afetados nestas condições. Assim, foi considerado que quanto maior o número de domicílios de uso ocasional, maior a capacidade adaptativa.

A fim de compor o modelo de capacidade adaptativa, a linha de costa foi segmentada em cada trecho dos setores censitários fronteiriços ao mar. Os valores equivalentes ao número de residentes, renda domiciliar e residência de uso ocasional foram então rebatidos para a linha de costa.

O número de residentes corresponde ao somatório dos moradores em domicílios particulares e coletivos. A renda domiciliar é representada pelo valor do somatório dos moradores em domicílios particulares permanentes e improvisados. A residência ocasional, por sua vez, constitui-se no somatório dos moradores em domicílios particulares permanentes de uso ocasional. Considerações acerca dos dados podem ser obtidas em IBGE (2010b) e IBGE (2011).

Os polígonos da malha digital, por apresentarem diferentes áreas e formatos, tornam inviável a comparação direta da capacidade adaptativa entre os setores. Para tal, foi realizada uma transformação na escala de valores através de uma relação entre a área dos setores censitários e a extensão de suas linhas de costa (Equação 2).

$$
\mathrm{y}=\mathrm{x} /(\mathrm{ab})
$$

onde, $\mathrm{x}=$ valor original da variável, $\mathrm{y}=$ valor $\mathrm{da}$ variável ajustado pelas variáveis a e b, a = comprimento do setor censitário em contato com o mar $(\mathrm{m})$ e $\mathrm{b}=$ área do setor censitário $\left(\mathrm{m}^{2}\right)$.

\section{Cálculos dos índices de suscetibilidade costeira (ISC), capacidade adaptativa (ICA) e vulnerabilidade costeira (IVC)}

O conjunto de variáveis selecionadas foi organizado em dois sub-modelos: suscetibilidade e capacidade adaptativa, tendo a vulnerabilidade final sido determinada a partir da sua integração (figura 3).

Todas as variáveis foram classificadas em 5 graus de suscetibilidade ou de capacidade adaptativa: muito baixo, baixo, médio, alto e muito alto. A hierarquização das variáveis quantitativas foi determinada pela divisão dos valores em quintis medida separatriz que divide os dados ordenados em 5 subconjuntos de dados de dimensão essencialmente igual (Piana et al. 2009).

Para a obtenção do índice final, a linha de costa foi segmentada manualmente a cada mudança de classe dos valores de ISC e ICA.

A vulnerabilidade costeira apresentará valores maiores em setores mais suscetíveis e com menor capacidade de adaptação. Portanto, a classe "muito alta" de suscetibilidade é associada ao grau 5 do IVC e as classes "alta", "média", "baixa" e "muito baixa" pelos graus 4, 3, 2 e 1, respectivamente. O contrário é válido para as classes de capacidade adaptativa, sendo a classe "muito alta" incorporada ao IVC como tendo grau 1 e as classes mais baixas representadas pelos graus mais altos. Por último, os valores de IVC também foram hierarquizados em quintis de vulnerabilidade.

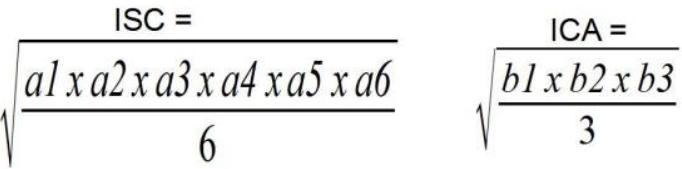

$$
\begin{aligned}
& \text { a1 } \rightarrow \text { tipo de linha de costa } \\
& \begin{array}{l|l}
\text { a } 2 \rightarrow \text { largura de praia } & \text { b1 } \rightarrow \text { população residente }
\end{array} \\
& \text { a } 3 \rightarrow \text { exposição às ondas } \quad \text { b2 } \rightarrow \text { renda domiciliar } \\
& \text { a } 4 \rightarrow \text { maré astronômica } \quad \text { b3 } \rightarrow \text { residência ocasional } \\
& \text { a } 5 \rightarrow \text { maré meteorológica } \\
& \text { a6 } \rightarrow \text { variação da linha de , } \\
& \text { costa } \quad \text { IVC }=\sqrt{\frac{I S C \times I C A}{2}}
\end{aligned}
$$

Figura 3: Relação entre as variáveis selecionadas para a determinação do índice de vulnerabilidade costeira.

Os segmentos de classes de linha de costa diferentes de "praia" também foram classificados para fins comparativos. Todavia, tiveram seu ISC calculado a partir de apenas 5 variáveis, excluindo-se a largura de praia. A capacidade adaptativa, por estar relacionada à presença humana, foi obtida somente para os tipos de linha de costa em que esta é mais expressiva: estrutura artificial e praia.

\section{Resultados}

Para a melhor visualização dos resultados, a localização das praias mencionadas ao longo do texto pode ser identificada pelas figuras 4 e 5 .

\section{Suscetibilidade}

As variáveis selecionadas e os seus valores de corte associados às classes de vulnerabilidade podem ser observados na tabela 4. Nela é representada a matriz de valores adotada para a classificação da área em cinco graus de suscetibilidade. À exceção do indicador "tipo de linha de costa", cujas classes foram definidas de modo qualitativo, paras as demais variáveis são apresentados os valores de corte obtidos pela aplicação do método dos quintis buscando-se, com isso, uma maior representatividade na distribuição espacial das classes propostas (Bonetti \& Woodroffe 2017). Devese destacar, todavia, que apesar desta técnica maximizar a representatividade das classes de suscetibilidade/capacidade adaptativa/vulnerabilidade, os valores obtidos e representados na tabela 4 só possuem efetividade para a base de dados e a área sob investigação. Desta forma, os valores de corte indicados como delimitadores de classes não se prestam para serem aplicados em outros estudos, devendo os mesmos serem calculados caso-a-caso.

A distribuição dos graus de suscetibilidade ao longo dos setores litorâneos definidos pelo GERCO-SC é apresentada na figura 6 . 

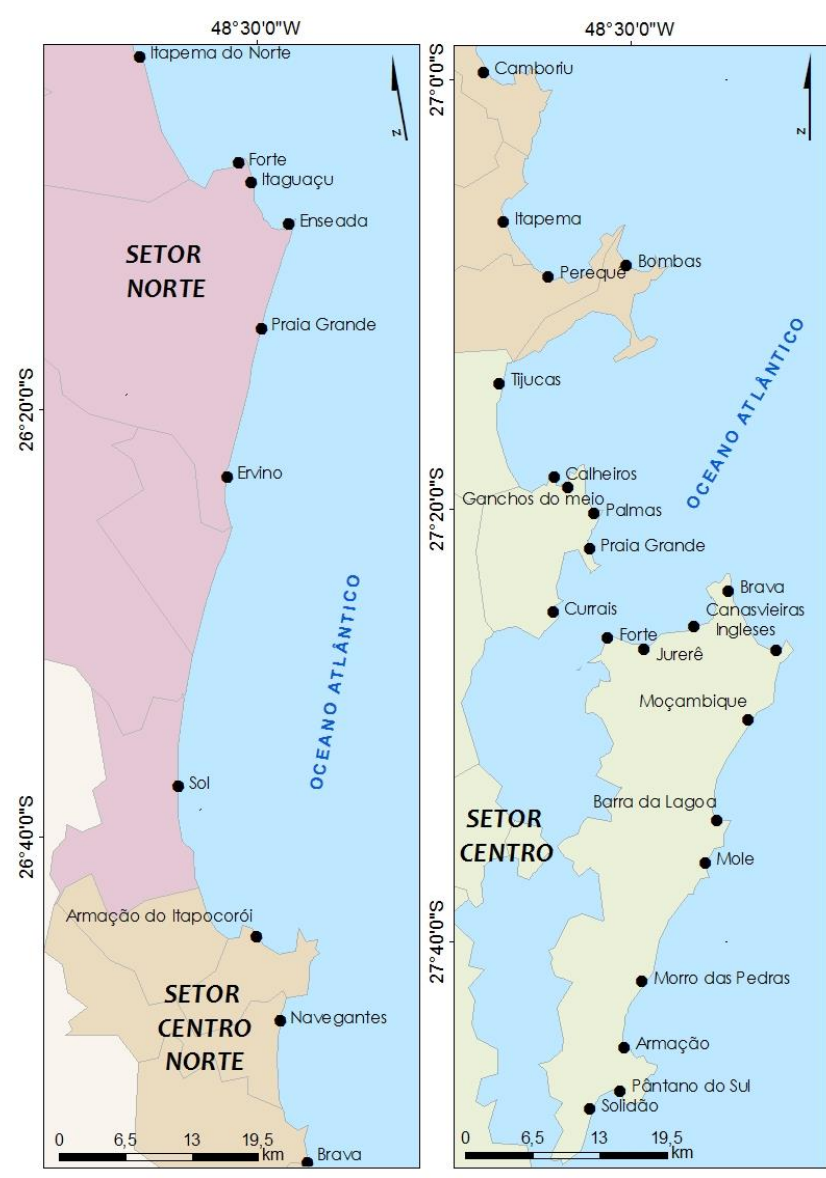

Figura 4: Localização de praias citadas nos setores Norte, CentroNorte e Centro.

Ambientes praiais, considerados de alta suscetibilidade devido a sua alta mobilidade sedimentar, representam $65,87 \%$ da linha de costa do estado. Compõem praticamente toda a extensão dos setores Norte e Sul, onde são intercalados por desembocaduras de estuários e lagunas. A segunda classe de tipo de linha de costa mais presente ao longo do litoral é a representada pelos costões rochosos $(30,77 \%)$, classificados como de grau de suscetibilidade muito baixo devido a sua mobilidade extremamente baixa, praticamente restritos aos setores Centro-Norte, Centro e Centro-Sul. Os demais tipos de linha de costa são pouco expressivos espacialmente. As estruturas artificiais representam apenas $2,21 \%$ da linha de costa, concentrando-se no setor Centro-Norte. Embora a presença de desembocaduras seja notória ao longo da linha de costa catarinense, estas são encontradas em apenas $0,94 \%$ desta em decorrência de suas pequenas dimensões. Os trechos de vegetação costeira (presenças localizadas de marismas, manguezais e vegetação de restinga no limite terra/água da linha de costa), além de apresentarem pequenas extensões, manifestam-se como o tipo de linha de costa minoritário $(0,21 \%)$, estando expressivamente localizados apenas no setor central, dado o elevado recorte de sua linha de costa.

No geral, as praias mais ao sul do estado são caracterizadas por maiores larguras quando

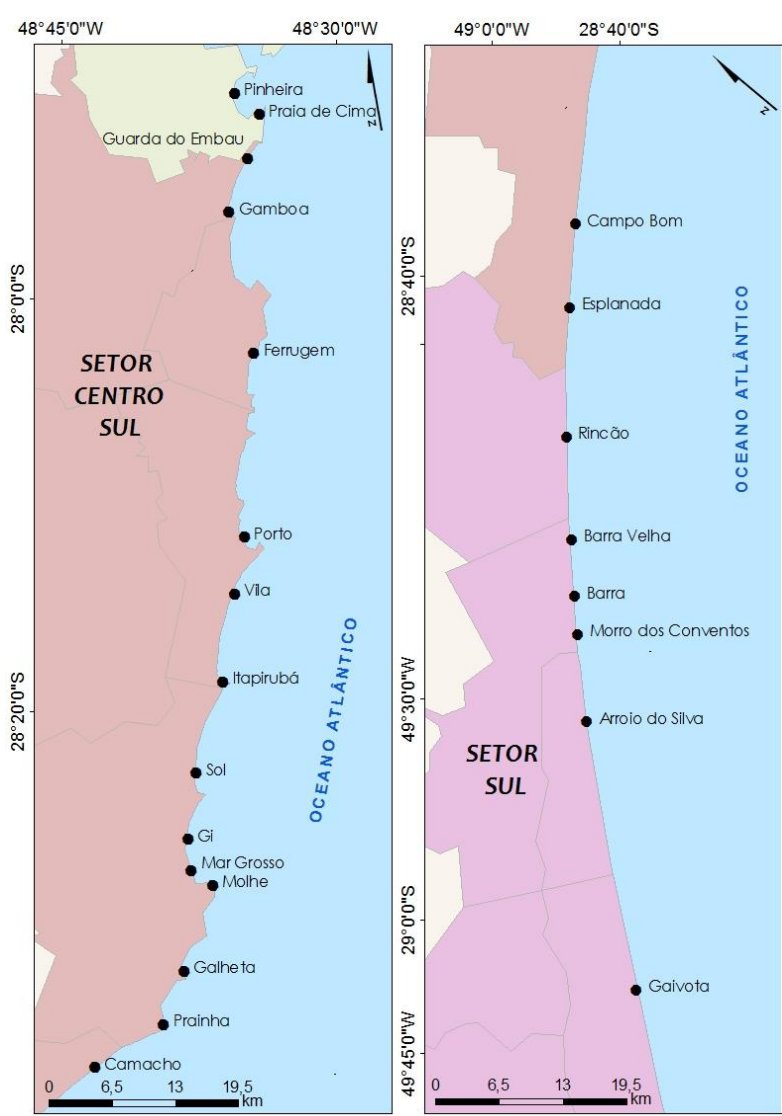

Figura 5: Localização de praias citadas nos setores Centro-Sul e Sul.

comparadas às praias dos demais setores. Os setores Sul e Centro-Sul são caracterizados pelos graus de suscetibilidade muito baixo, baixo e médio. Nestes, os graus alto e muito alto são significativos apenas em sua porção norte. $\mathrm{O}$ setor Centro apresenta-se bem diversificado em relação à largura de praia, com consideráveis trechos de faixa de areia muito estreita nas localidades de: Praia da Guarda e Praia de Cima, sul das praias da Armação e Ingleses, oeste de Canasvieiras, trecho da Praia do Forte e em uma grande extensão do litoral do município de Governador Celso Ramos. Praias estreitas, com alto grau de suscetibilidade, caracterizam o setor Norte. O CentroNorte, em comparação aos demais setores, possui a maior extensão de linha de costa classificada no grau de suscetibilidade muito alto.

A espacialização da amplitude de maré astronômica ao longo da linha de costa indicou um padrão decrescente de norte a sul, variando entre $0,51 \mathrm{~m}$ (extremo norte) e $0,18 \mathrm{~m}$ (extremo sul).

Em relação à maré meteorológica, os maiores valores foram encontrados nos setores Norte e Sul, variando de $1,32 \mathrm{~m}$ a $1,50 \mathrm{~m}$. No outro extremo estão os setores Centro e Centro-Sul, com quase todas as amplitudes situadas no intervalo de $1,1 \mathrm{~m}$ a $1,27 \mathrm{~m}$. Foi observado um comportamento decrescente da amplitude de maré meteorológica do setor Norte até a metade do setor Centro-Sul. A partir deste ponto os valores começam a crescer novamente, sendo o setor Sul representado 
GRAUS DE SUSCETIBILIDADE DAS VARIÁVEIS DO MEIO FíSICO POR SETOR DO GERCO/SC

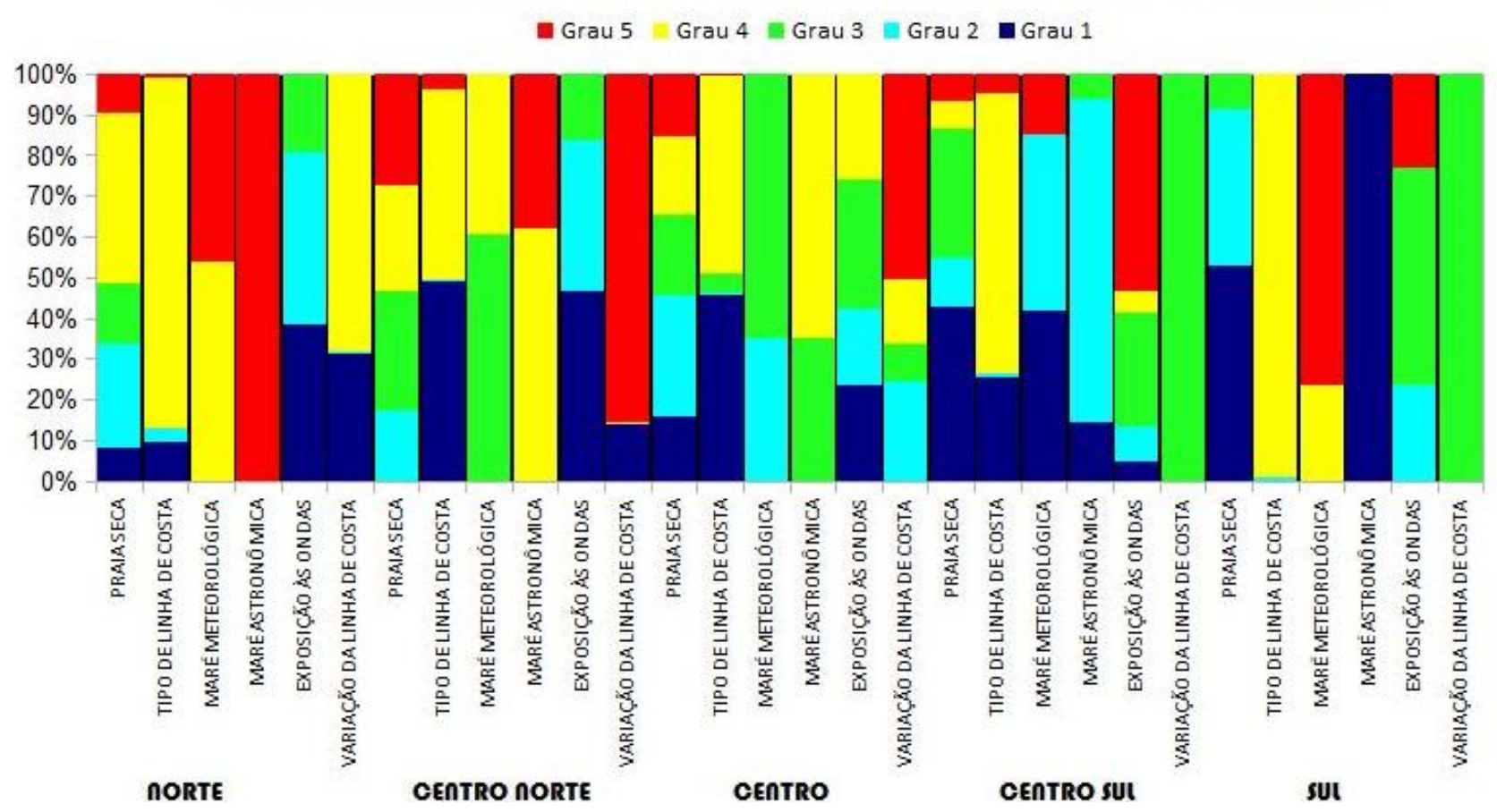

Figura 6: Distribuição dos graus de suscetibilidade costeira nos setores do GERCO/SC.

Tabela 4: Matriz para a determinação do Índice de Suscetibilidade Costeira. (*) Obtida conforme tabela 1.

\begin{tabular}{|c|c|c|c|c|c|c|c|}
\hline ID & $\begin{array}{c}\text { Indicador de } \\
\text { suscetibilidade }\end{array}$ & Fonte & $\begin{array}{l}1 \text { (Muito } \\
\text { baixo) }\end{array}$ & 2 (Baixo) & 3 (Médio) & 4 (Alto) & 5 (Muito alto) \\
\hline $\mathbf{a}$ & $\begin{array}{l}\text { Tipo de linha de } \\
\text { costa }\end{array}$ & Imagens Quickbird & Costão rochoso & $\begin{array}{l}\text { Desembocadura de } \\
\text { rio }\end{array}$ & $\begin{array}{l}\text { Vegetação } \\
\text { Costeira }\end{array}$ & Praia & $\begin{array}{l}\text { Estrutura } \\
\text { Artificial }\end{array}$ \\
\hline b & Largura de praia (m) & Imagens Quickbird & $31,55-177,5$ & $22,88-31,54$ & $15,65-22,87$ & $9,65-15,64$ & $0-9,64$ \\
\hline c & $\begin{array}{c}\text { Variação da linha de } \\
\text { costa (m/ano) }\end{array}$ & $\begin{array}{l}\text { Fotos e imagens aéreas (1957, } \\
\text { 1978, 1995, 2011); bibliografia }\end{array}$ & $-0,13$ & $-0,18$ & $-0,25$ e $-0,30$ & $-0,35$ & $-0,73$ \\
\hline d & Exposição às ondas * & $\begin{array}{c}\text { Find Polilyne Angle; Visualizador } \\
\text { web do projeto Estudio regional de } \\
\text { los efectos del cambio climático } \\
\text { em la costa de America Latina y el } \\
\text { Caribe }\end{array}$ & $1,00-3,00$ & $3,01-3,66$ & $3,67-4,33$ & $4,34-4,66$ & $4,67-5,00$ \\
\hline e & $\begin{array}{l}\text { Maré astronômica } \\
\text { (m) }\end{array}$ & \multirow{2}{*}{$\begin{array}{l}\text { Visualizador web do projeto } \\
\text { Estudio regional de los efectos del } \\
\text { cambio climático em la costa de } \\
\text { America Latina y el Caribe }\end{array}$} & $0,18-0,19$ & $0,20-0,23$ & $0,24-0,28$ & $0,29-0,33$ & $0,34-0,51$ \\
\hline $\mathbf{f}$ & $\begin{array}{l}\text { Maré meteorológica } \\
(\mathrm{m})\end{array}$ & & 1,1 & $1,11-1,19$ & $1,20-1,27$ & $1,28-1,33$ & $1,34-1,50$ \\
\hline
\end{tabular}

Espacialmente, a altura de onda apresentou um comportamento crescente do setor Norte ao início do setor Sul, onde passou a decrescer. O setor Centro-Sul, exposto quase em sua totalidade a ondas dos quadrantes sul e leste, recebe as maiores alturas de onda $(7,19 \mathrm{~m}$ a $7,61 \mathrm{~m})$. Este é seguido pelo setor Centro, exposto predominantemente às ondas de leste, com altura máxima de 7,13 $\mathrm{m}$. As menores alturas de onda são encontradas para os segmentos situados entre o extremo norte de Santa Catarina e o norte do setor Centro, bem como em quase toda a extensão da linha de costa do setor Sul - com exceção do extremo norte deste setor. Nestes trechos, a classe de suscetibilidade muito alta (maiores alturas de onda) esteve ausente, enquanto a classe alta foi observada apenas em pequenas extensões do município de Governador Celso Ramos - localizado no norte do setor Centro.

A exposição às ondas varia segundo a altura de onda e a orientação da linha de costa em relação ao fluxo médio de energia. Ao longo de toda a costa catarinense o fluxo médio de energia de onda se direcionou para sudeste. Desta forma, os segmentos expostos a esta direção foram considerados mais suscetíveis, atribuindo-lhes a classe "muito alta". Posto isso, podese observar que o setor Centro-Norte apresenta segmentos com valores muito baixos de exposição, coincidentes com os trechos da linha de costa com menores alturas de onda e abrigados, em sua maior extensão, em relação à direção sudeste.

A taxa de variação da linha de costa para os setores Centro-Sul e Sul indicou suscetibilidade média, 
representada pelos valores: $-0,30 \mathrm{~m} /$ ano (setor Sul e parte do setor Centro-Sul) e - $0,25 \mathrm{~m} /$ ano (parte do setor Centro-Sul). As linhas de costa que apresentaram menores variações, embora também estejam em processo de retrogradação, estão localizadas no sul do setor Centro ( $-0,18 \mathrm{~m} / \mathrm{ano}$, suscetibilidade baixa), no sul do setor Norte e no extremo norte do setor CentroNorte (-0,13 m/ano, suscetibilidade muito baixa). O setor Centro-Norte e o norte do setor Centro apresentaram o maior cenário de retrogradação da linha de costa, classificados em suscetibilidade muito alta ($0,73 \mathrm{~m} / \mathrm{ano}$ ). Também apresentaram taxas elevadas o norte do setor Norte e as praias do nordeste da Ilha de Santa Catarina (-0,35 m/ano, alta suscetibilidade).

A integração espacial entre as variáveis físicas, através da aplicação do ISC, resultou no modelo de suscetibilidade apresentado na figura 7.

O modelo de suscetibilidade apresentou forte predomínio das classes alta e muito alta no trecho situado do extremo norte do Estado de Santa Catarina à metade do setor Centro. Em locais onde a linha de costa é representada por costões rochosos, no entanto, o modelo de suscetibilidade se expressa majoritariamente nas classes baixa e muito baixa. Os setores Centro-Sul e Sul apresentaram as maiores extensões de linha de costa classificadas em suscetibilidade inferior ao médio grau e foram marcados pela ausência da classe muito alta. O setor Centro apresentou uma região a norte classificada predominantemente entre os graus de médio a muito alto sobre os segmentos praiais, e outra - a sul - com predomínio das classes baixa, média e alta sobre as praias e uma forte presença de costões rochosos, em sua maioria classificados em suscetibilidade muito baixa. Os segmentos litorâneos que se destacam pelos graus alto e muito alto, situam-se nas localidades de: municípios de Itapoá e São Francisco do Sul, Praia de Navegantes à Praia de Balneário Camboriú, Praia de Itapema, municípios de Bombinhas e Governador Celso Ramos, norte da Ilha de Santa Catarina, leste da Ilha de Santa Catarina (do sul dos Ingleses ao norte da Praia Mole).

Nos setores Sul e Centro-Sul, alguns trechos de suscetibilidade alta - embora de pequena extensão foram encontrados nas praias de: Gamboa, Ferrugem, Barra, trecho da Guarda do Embaú, praias do Sol, do
Gi e da Galheta (setor Centro-Sul); Camacho, Campo Bom, trechos entre Barra Velha e Rincão e entre Morro dos Conventos e Arroio do Silva (setor Sul)

\section{Capacidade Adaptativa}

Os intervalos de valores das variáveis obtidas a partir de dados do IBGE são apresentados na tabela 5. A figura 8, por sua vez, apresenta a distribuição dos cinco graus de capacidade adaptativa ao longo do litoral catarinense.

A distribuição da população se apresenta bastante heterogênea ao longo da costa catarinense. Enquanto uma baixa extensão da linha de costa é intensamente ocupada, uma grande extensão é identificada pelos quintis que representam menores números de residentes.

A existência de áreas prioritárias de ocupação está relacionada à tendência de menor concentração de pessoas sobre os trechos da orla expostos às direções de maiores fluxos de energia (principalmente as direções sudeste e sul) - padrão evidente nos setores Norte, Centro e Sul do estado. Por outro lado, uma ocupação mais intensa é observada em trechos abrigados desses fluxos de energia mais intensos, como observado nos setores Centro e Centro-Norte.

A distribuição espacial do rendimento domiciliar também se apresentou bastante desigual, com forte concentração de renda sobre pequenas extensões da linha de costa.

O setor Centro-Norte apresentou os maiores valores de rendimento domiciliar (graus alto e muito alto de capacidade adaptativa), estando os maiores trechos localizados nas praias de: Navegantes, Itapema, Balneário Camboriú, Bombinhas e Bombas. Nos demais setores, podem ser observados trechos poucos extensos classificados nas classes alta e muito alta, estando os mais evidentes nas praias de: Itapema do norte, Praia da Enseada, Praia do Sol (setor Norte); Calheiros, Ganchos do Meio, Canasvieiras, Jurerê, Ingleses, sul da Barra da Lagoa, Armação, Morro das Pedras, Mole, Pântano do Sul, Solidão, sul da Pinheira (setor Centro); praias do Porto e da Vila, Praia do Mar Grosso, do Camacho (setor Centro-Sul); trechos dos Balneários Gaivota e Arroio do Silva (setor Sul). 

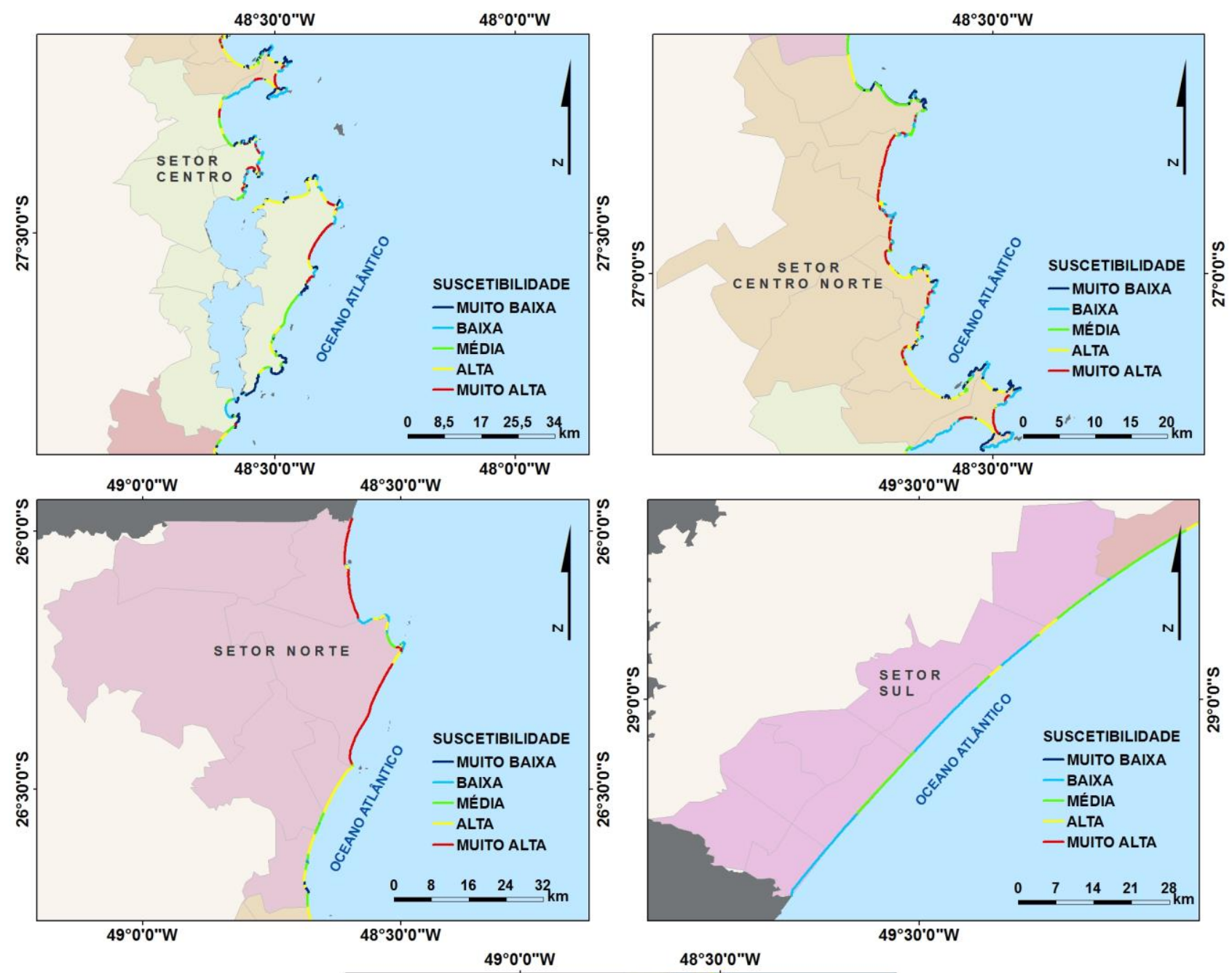

$49^{\circ} 30^{\prime} 0^{\prime \prime} \mathrm{W}$

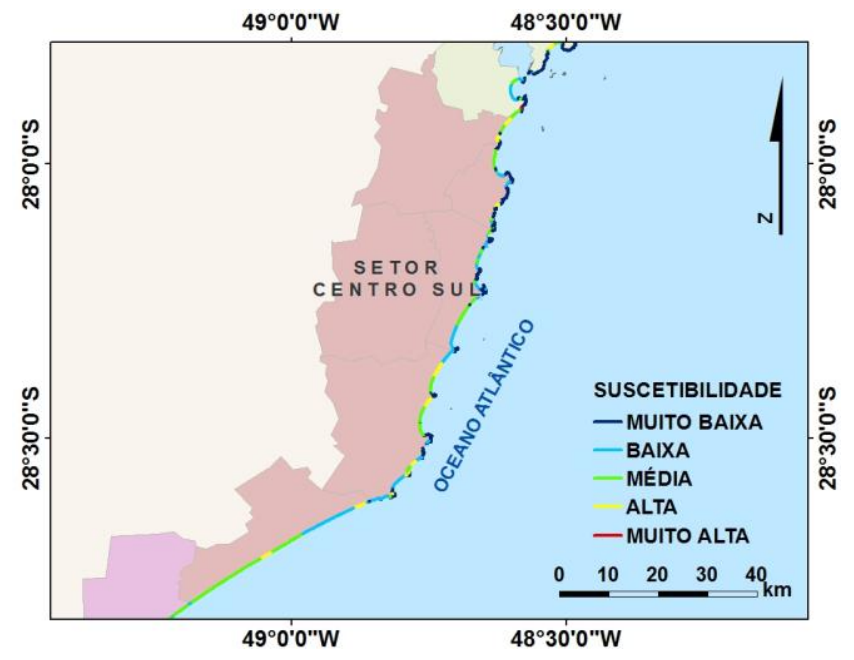

Figura 7: Modelo de suscetibilidade.

Tabela 5: Intervalo de variação dos descritores selecionados para a construção do Índice de Capacidade Adaptativa.

\begin{tabular}{|c|c|c|}
\hline \multicolumn{3}{|c|}{ Intervalo de Variação dos Descritores } \\
\hline ID & Descritor & $\begin{array}{c}\text { Intervalo de } \\
\text { variação }\end{array}$ \\
\hline a & População residente & $2-1753$ \\
\hline b & $\begin{array}{c}\text { Rendimento } \\
\text { domiciliar }\end{array}$ & $0-2910496$ \\
\hline c & $\begin{array}{c}\text { Residência de uso } \\
\text { ocasional }\end{array}$ & $0-1000$ \\
\hline
\end{tabular}

A linha de costa do Estado de Santa Catarina apresentou, em sua maior extensão, baixos números de residência ocasional. Todavia, alguns pequenos trechos apresentaram valores muito acima da média.

Uma maior quantidade de domicílios utilizados como segunda moradia foi encontrada em trechos do setor Centro-Norte, coincidindo com os segmentos de maior concentração de renda. Exemplos são as praias de Balneário Camboriú, Navegantes, Itapema e Bombas. 


\section{GRAUS DE CAPACIDADE ADAPTATIVA DAS VARIÁVEIS SOCIOECONÔMICAS POR SETOR DO GERCO/SC}

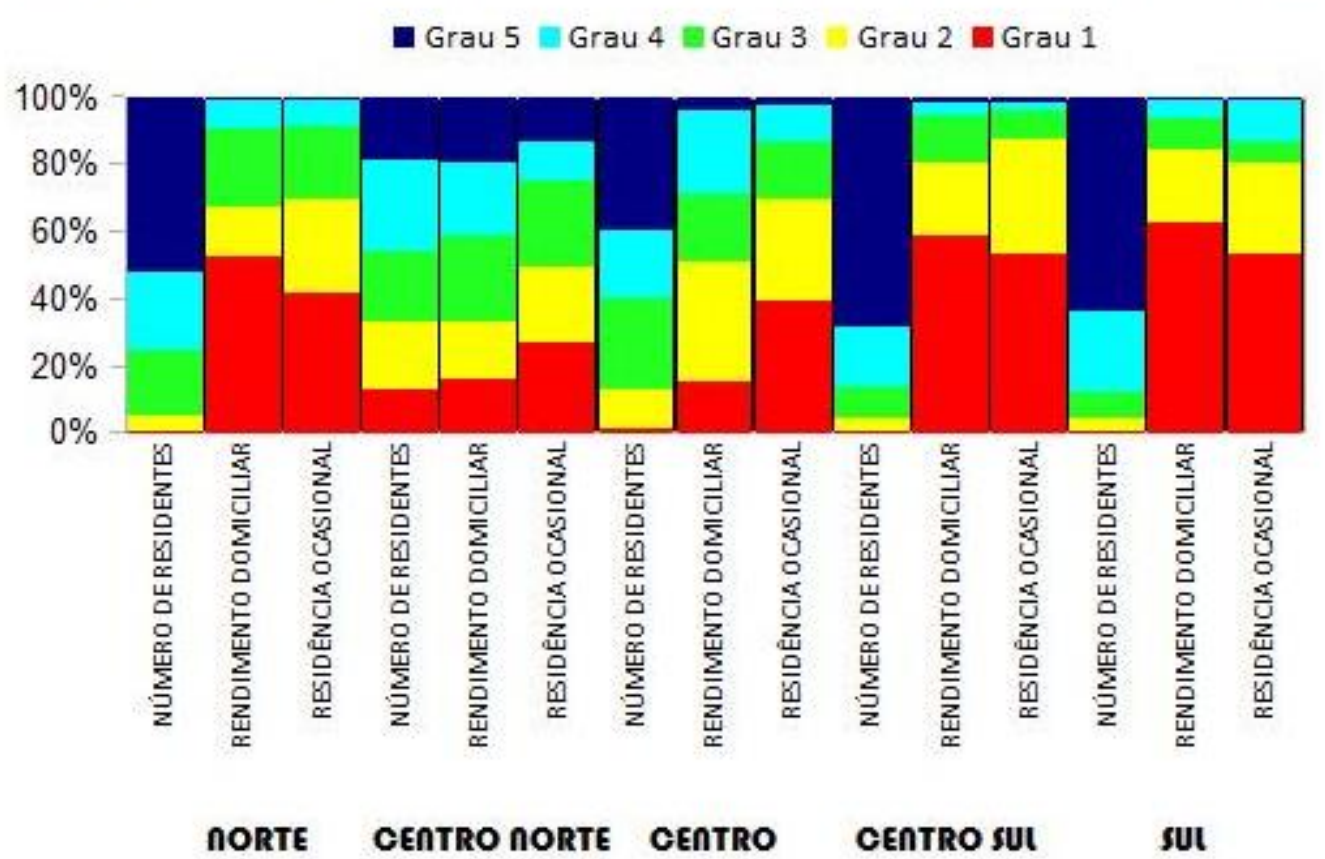

Figure 8: Distribuição dos graus de capacidade adaptativa nos setores do GERCO/SC. .

Nos demais setores a presença de residências de uso ocasional é praticamente inexpressiva. Os trechos onde a presença se faz mais evidente estão situados nas localidades de: Itapema do Norte, Praia do Sol, da Enseada e de Itaguaçu (setor Norte); norte da Ilha de Santa Catarina (Florianópolis), Pinheira (setor Centro); Prainha e trechos do Camacho e Esplanada (setor Centro-Sul); trechos das praias do Rincão e dos Balneários Gaivota e Arroio do Silva (setor Sul).

O modelo de capacidade adaptativa (figura 9) apresentou segmentos de linha de costa com graus variando entre 1 e 5 em todos os setores do GERCO/SC. Nota-se, porém, que os maiores valores (classes alta e muito alta) são mais expressivos nos setores Centro e Centro-Norte, sobre os segmentos de renda domiciliar elevada e de maior número de residências de uso ocasional. Partindo de uma visão mais generalizada, uma maior capacidade adaptativa (classes alta e, principalmente, muito alta) é verificada para os grandes balneários.

Os segmentos que mais se destacam pelos altos valores se situam nas localidades de: balneários Rincão, Arroio do Silva e Gaivota (setor Sul); Balneário Esplanada, Campo Bom, Camacho, sul da Barra do Molhe, Itapirubá (setor Centro-Sul); Pinheira, Solidão, Canasvieiras, Brava, Ingleses, sul de Palmas (setor Centro); Bombas, Bombinhas, Itapema, Perequê, sul da praia de Balneário Camboriú, trechos de Navegantes e Armação do Itapocorói (setor CentroNorte); Praia do Sol, sul da Praia da Enseada e Itapema do Norte (setor Norte).
No geral, os segmentos mais populosos correspondem aos de maior rendimento e possuem um maior número de residências de uso ocasional. Os dois últimos fatores são responsáveis pela alta capacidade adaptativa encontrada para estes trechos.

\section{Vulnerabilidade}

Os setores mais vulneráveis foram encontrados nos trechos centrais dos setores Norte e Centro-Norte e em segmentos no norte do setor Centro (figura 10).

O setor Norte, identificado como o mais vulnerável, apresentou os maiores percentuais de linha de costa classificados nos graus de vulnerabilidade alto e muito alto. Os trechos mais evidentes localizam-se nas praias de: Praia Grande, Ervino, região a norte da Praia do Sol, Praia do Forte e Sul de Itapema do Norte.

No setor Centro-Norte, os graus de vulnerabilidade encontrados ao longo dos maiores trechos praiais contínuos - como os dos municípios de Balneário Camboriú, Itapema e Navegantes - foram menores, em sua maioria, quando comparados aos seus graus de suscetibilidade. Já os trechos praiais pequenos, intercalados por costões rochosos, apresentaram um cenário de alta vulnerabilidade, em decorrência da alta suscetibilidade e da baixa capacidade adaptativa sobre estes locais. O setor também é marcado pela presença de grandes balneários onde, apesar de suas elevadas densidades populacionais, a capacidade adaptativa foi representada pelas classes alta e muito alta em um grande percentual de suas extensões de linha de costa colaborando para a redução da vulnerabilidade. 

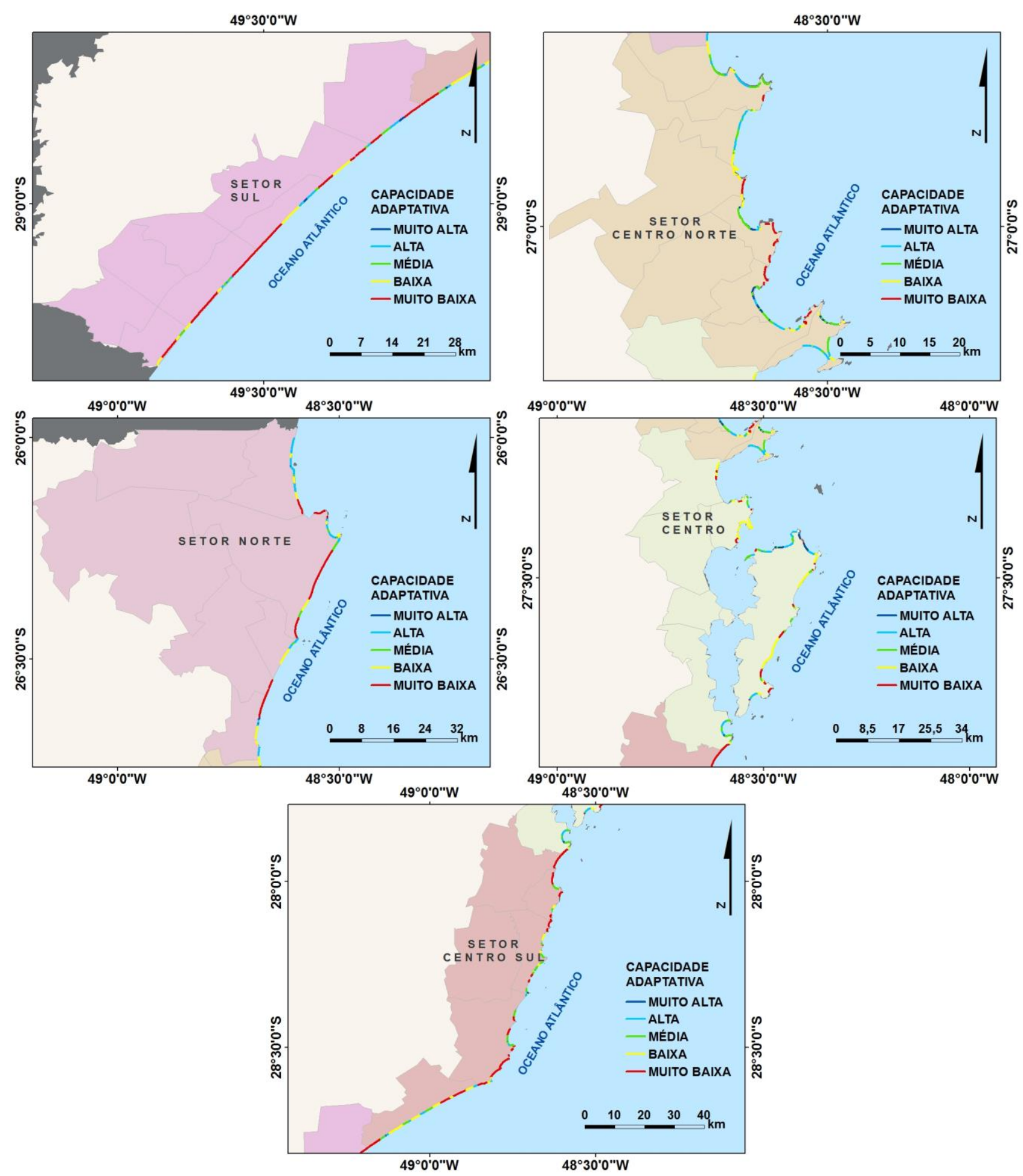

Figura 9: Modelo de capacidade adaptativa.

e são ocupados ao longo de todo o ano; e não de forma ocasional.

Por outro lado, as praias do norte da Ilha de Santa Catarina, embora tenham apresentado valores altos de suscetibilidade, manifestaram vulnerabilidade predominantemente de grau muito baixo, em decorrência de seus elevados valores de capacidade adaptativa. Um bom exemplo é a praia de Canasvieiras, onde embora haja um grande número de residentes, estes possuem uma renda bastante elevada e, em muitos casos, até mesmo uma segunda moradia. 
Os setores Sul e Centro-Sul apresentaram aproximadamente $90 \%$ da extensão de suas linhas de costa classificada nos graus de vulnerabilidade de muito baixo a médio. Representaram os setores menos vulneráveis e foram marcados pela ausência da classe de vulnerabilidade muito alta. Embora o baixo grau de
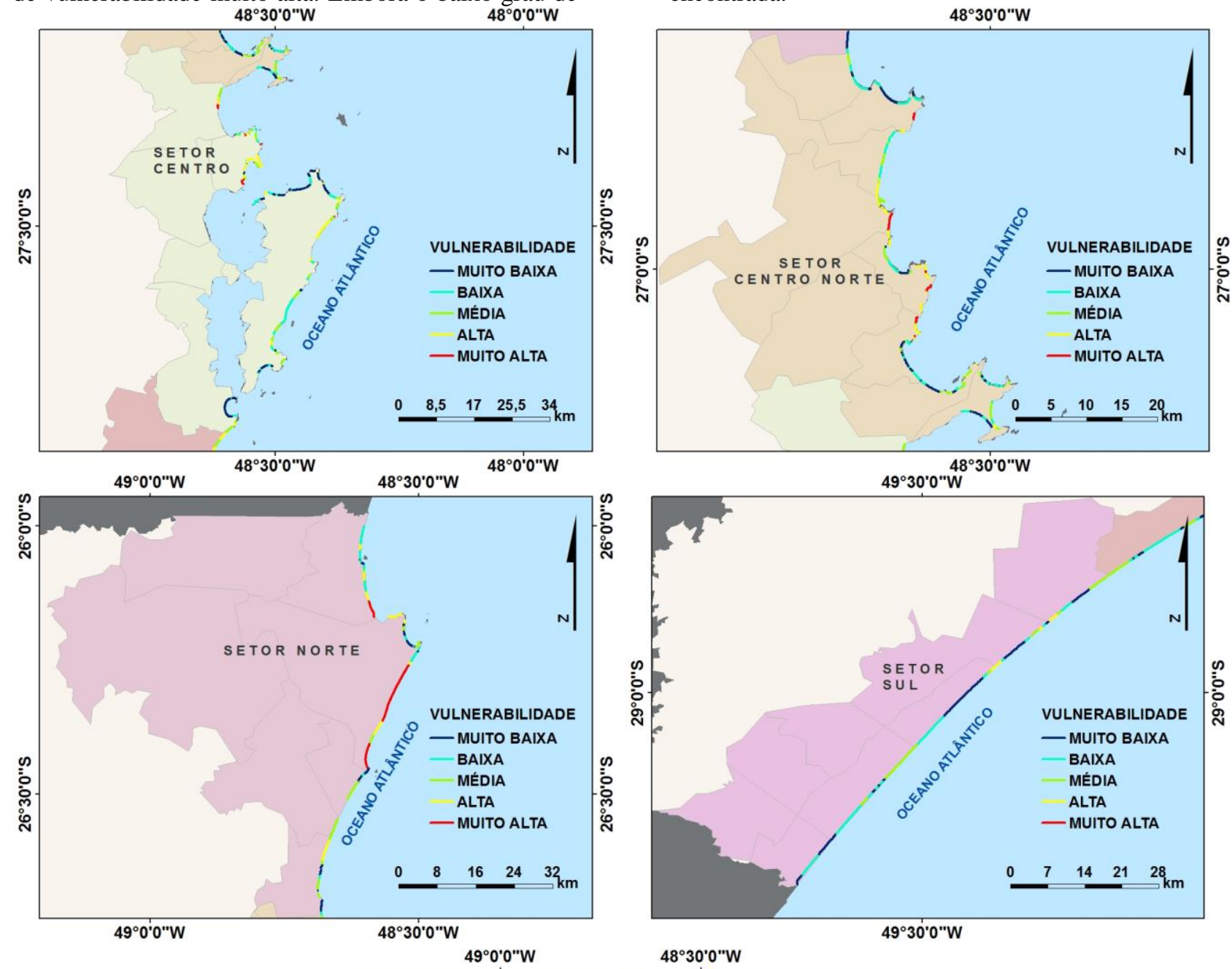

capacidade adaptativa tenha sido predominante sobre estes setores (excetuando-se os grandes balneários, como os de Rincão, Arroio do Silva e Gaivota), as condições ambientais e os aspectos físicos da linha de costa foram determinantes para a baixa vulnerabilidade encontrada.
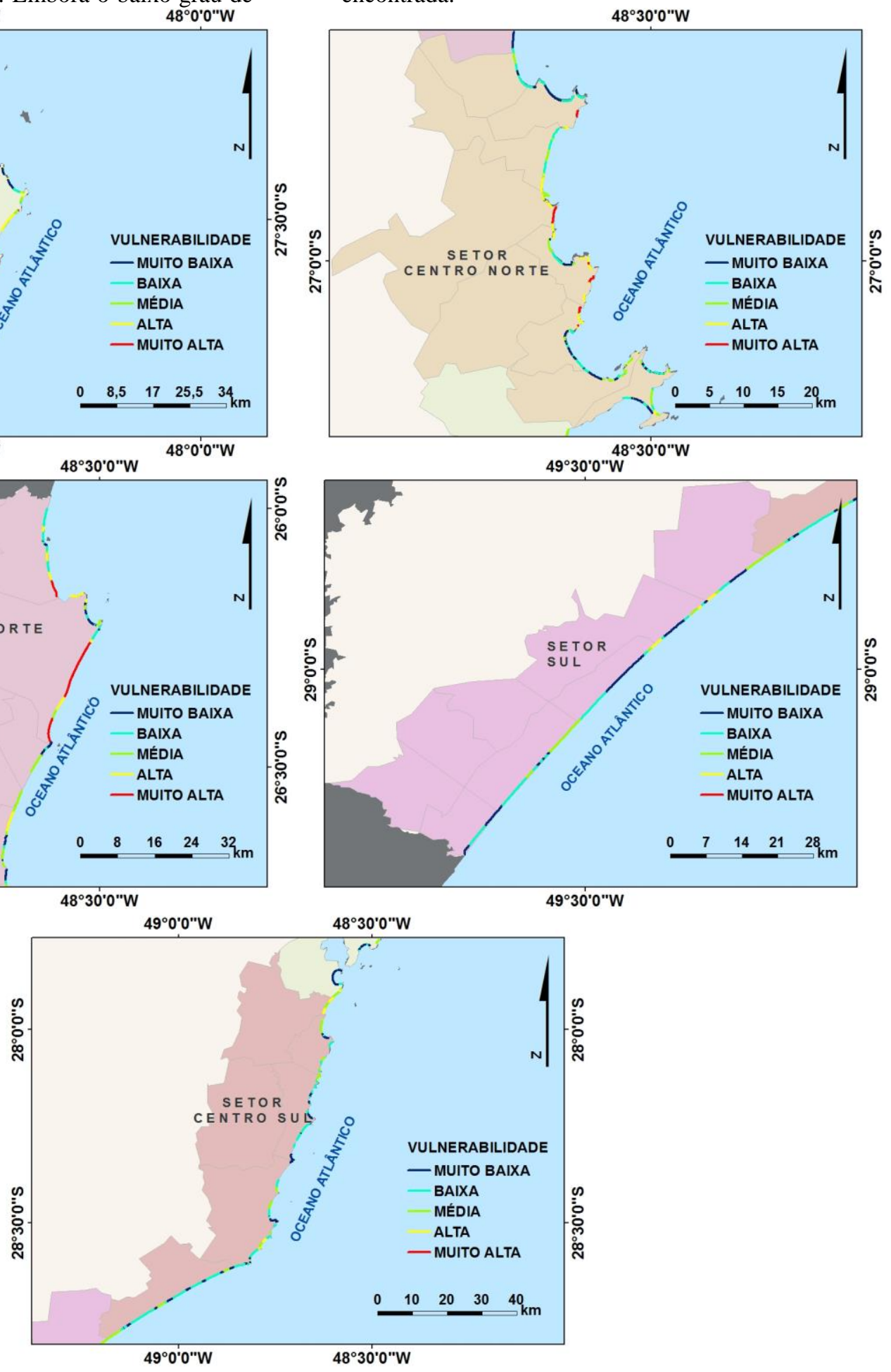

Figura 10: Modelo de vulnerabilidade.

\section{Discussão}

A metodologia consistiu na elaboração de um índice multicritério aplicado a partir de técnicas de análise espacial. Para tanto, foi proposto um índice de vulnerabilidade costeira (IVC), adaptado da abordagem inicialmente proposta por Gornitz (1991) - o Coastal Vulnerability Index (CVI).

Pode-se considerar que existe consenso quanto ao fato de que análises de vulnerabilidade devem abranger 
características naturais, de infraestrutura, sociais e econômicas. Todavia, segundo Abuodha \& Woodroffe (2010a), as metodologias para combinação destes elementos não são amplamente difundidas, sendo pouco empregadas pela comunidade técnica e científica. Em função disso, mapas resultantes de modelos de análise espacial da vulnerabilidade podem acarretar em uma incompletude na avaliação dos efeitos dos perigos costeiros e em planos de mitigação de baixa efetividade.

A inclusão de fatores socioeconômicos em avaliações de vulnerabilidade costeira tem sido aplicada e indicada como de grande relevância por diversos autores (McLaughlin et al. 2002, Boruff et al. 2005, Nguyen \& Woodroffe 2015). No entanto, como observado por McLaughlin et al. (2002), persistem dificuldades em sua incorporação sobretudo devido à carência de dados censitários em escala adequada e à falta de clareza da representatividade das variáveis de natureza social e econômica.

Visando fomentar a discussão sobre a influência de fatores socioeconômicos na determinação da vulnerabilidade, neste trabalho foram apresentados 3 modelos finais que retratam isoladamente a influência regional de fatores físicos (modelo de suscetibilidade), dos fatores socioeconômicos (modelo de capacidade adaptativa) e, por fim, a integração entre ambos (modelo de vulnerabilidade).

Os setores mais vulneráveis ao longo da linha de costa do Estado de Santa Catarina foram identificados em trechos centrais dos setores Norte e Centro-Norte e em segmentos no norte do setor Centro.

Os fatores socioeconômicos foram bastante relevantes sobre os grandes balneários, destacando-se os do setor Centro-Norte, nos municípios de Balneário Camboriú, Itapema e Navegantes. Nestes setores, a vulnerabilidade apresentou graus inferiores à suscetibilidade, justificados pela renda elevada e, secundariamente, pela forte presença de domicílios de uso ocasional. $\mathrm{O}$ padrão observado nos balneários mais expressivos do Centro-Norte sustenta a ideia de que é possível estar exposto/ser suscetível e não ser vulnerável.

Por outro lado, os setores Sul e Centro-Sul, embora tenham apresentado baixos graus de capacidade adaptativa, foram os menos vulneráveis; indicando a maior relevância dos fatores físicos sobre estes locais.

Apesar das dificuldades em se efetuar a validação de modelos de vulnerabilidade costeira (Bonetti \& Woodroffe 2017), pode-se afirmar que a representatividade do esquema de integração de variáveis aqui proposto foi satisfatória. O modelo desenvolvido nesta pesquisa apresentou menores graus de vulnerabilidade em setores com menos relatos de danos costeiros, conforme observado nos relatórios de danos da defesa civil (AVADANS; Rudorff et al. 2014), e também sobre extensos balneários com alto grau de desenvolvimento econômico, cuja recuperação após eventos de erosão e inundação aguda tem historicamente se dado em períodos relativamente curtos, ainda que ali ocorram danos frequentes.

É importante ressaltar que os dados preexistentes das taxas de variação da linha de costa não são de todo compatíveis. Estes representam escalas temporais variadas, foram calculados a partir de métodos e indicadores de linha de costa alternativos e tiveram suas incertezas definidas segundo diferentes critérios. Em particular, não deve ser negligenciada a dificuldade em se definir um indicador de linha de costa suficientemente preciso e reconhecível na escala de trabalho adotada. Todavia, considerando que a integração desta variável a índices de vulnerabilidade é importante como indicativo da tendência de evolução morfológica local, optou-se pela sua manutenção, não obstante as limitações apontadas. Particularmente em Santa Catarina, dadas as características físicas anteriormente descritas, este indicador tem sido o de maior emprego na literatura regional (Vieira da Silva et al. 2016).

Reconhece-se também que o modelo de capacidade adaptativa proposto apresenta certa subjetividade, especialmente quanto às variáveis de entrada. Seria desejável a inclusão de um maior número de variáveis socioeconômicas independentes, que não possuam uma relação direta como a observada entre o número de residentes e o rendimento domiciliar dos setores. A atribuição de pesos às variáveis seria outra alternativa para minimizar essa amplificação dos valores de capacidade adaptativa ocasionada por variáveis diretamente relacionadas (Szlafsztein \& Sterr 2007; Nguyen \& Woodroffe 2015).

Destaca-se igualmente uma importante limitação dos dados socioeconômicos disponíveis, cuja representatividade em maior escala se dá através dos setores censitários. Estes, por possuírem geometria irregular e associarem valores únicos a áreas que podem ser relativamente extensas, por vezes criam resultados irreais. Um exemplo é a Praia de Moçambique (em Florianópolis), anteriormente citada. $\mathrm{O}$ modelo atribuiu à mesma uma condição de alta vulnerabilidade. Todavia, este trecho se situa no interior de um Parque Florestal Estadual sem ocupação junto à orla, podendo sua vulnerabilidade ser considerada nula. A capacidade adaptativa calculada refletiu os resultados de uma população assentada distante da linha de costa, devido às características do setor censitário que engloba o local. Apesar de ter-se tentado minimizar esse efeito através da normalização dos dados pela relação entre área e extensão da linha de costa de cada setor, o problema persiste em algumas situações. Uma outra abordagem, talvez incorporando a localização das manchas urbanas obtidas por classificação de imagens de satélite, poderia ser adotada em estudos voltados a ações específicas de manejo.

A análise comparativa entre os resultados dos diversos estudos de vulnerabilidade gerados para as praias de SC não é trivial por uma série de limitações. Entre elas, cita-se a liberdade dos autores na seleção 
das variáveis, dos intervalos de corte e do tipo de modelo adotado, além do anteriormente mencionado reescalonamento dos intervalos de classe de vulnerabilidade para o histograma local que ocorre quando se adota o método dos quantis. Assim, a rigor cada estudo é significativo nos limites dos pressupostos adotados por seus autores, inexistindo até o momento estratégias claras que permitam sua comparabilidade (Bonetti \& Woodroffe 2017).

A avaliação aqui apresentada, portanto, deve ser entendida como uma aproximação geral de áreas costeiras potencialmente vulneráveis a eventos de erosão e inundação costeira e poderia ser comparada à etapa First Pass proposta por Sharples \& Mount (2009). Segundo os autores, um próximo estágio no desenvolvimento de avaliações de impactos costeiros deve abranger um estudo detalhado das energias disponíveis para gerá-los. Para tanto, é recomendável que seja feita uma avaliação da exposição da linha de costa através de modelagem numérica, que analise de forma integrada os processos costeiros de marés, ondas e transporte de sedimentos.

Da mesma forma, ainda são poucos os estudos que detalharam a representatividade dos vários indicadores socioeconômicos disponíveis na determinação da capacidade adaptativa. Espera-se que novas pesquisas sobre o assunto permitam o aperfeiçoamento do modelo aqui proposto.

\section{Conclusões}

Neste trabalho foi proposta, a partir de uma adaptação metodológica, uma classificação da vulnerabilidade costeira aos efeitos de ondas de tempestade e marés meteorológicas para o Estado de Santa Catarina.

Até o momento a vulnerabilidade costeira não havia sido analisada na escala estadual. A mesma foi aqui obtida a partir da integração de dados físicos e socioeconômicos disponíveis a nível regional e representativos dos principais perigos aos quais a zona costeira do estado encontra-se exposta.

A abordagem utilizada possui potencial uso prático no planejamento e gerenciamento da zona costeira, com a vantagem de ser relativamente rápida e de baixo custo comparativamente às abordagens baseadas em métodos diretos, por exemplo pelo uso de geoindicadores (Rudorff \& Bonetti 2010).

Embora estudos de suscetibilidade e vulnerabilidade locais tenham sido anteriormente desenvolvidos para praias de Santa Catarina (Mazzer 2007, Rudorff \& Bonetti 2010, Muler \& Bonetti 2014), a efetiva comparabilidade dos resultados para diferentes trechos costeiros do estado só se tornou possível através da aplicação de uma classificação única de suscetibilidade, capacidade adaptativa e vulnerabilidade obtidos para o litoral catarinense como um todo.

O reconhecimento da vulnerabilidade relativa entre trechos amplos do litoral catarinense poderá auxiliar na definição de prioridades de gestão (Abuodha \&
Woodroffe 2010a) que busquem a minimização dos elevados números de pessoas afetadas e perdas econômicas apontados por Krueger (2011) e Rudorff et al. (2014) em função da recorrência de ressacas.

A pesquisa apresentada conferiu especial atenção a lacunas em estudos de vulnerabilidade costeira apontadas por diversos autores (Gornitz 1991, Muler \& Bonetti 2014, Bonetti \& Woodroffe 2017), entre elas: 1) a priorização da exposição da costa em relação às direções predominantes de incidência de energia - e não apenas pela simples incorporação da altura de onda; e 2) a apresentação de uma solução metodológica para a incorporação de variáveis socioeconômicas ao índice originalmente proposto por Gornitz (1991), visando a representação efetiva da vulnerabilidade, ou seja, da propensão de setores costeiros sofrerem perdas socioeconômicas devido à ação de um perigo.

As representações cartográficas obtidas permitem que se identifiquem os trechos costeiros mais vulneráveis, sobre os quais estudos de maior resolução espacial poderão ser desenvolvidos visando a implementação de medidas concretas de proteção à costa.

O monitoramento regular dessas áreas críticas, classificadas nos graus mais elevados de vulnerabilidade, poderá igualmente fomentar programas eficientes de apoio a medidas de prevenção e mitigação. Complementarmente, a comparação da evolução dos níveis de vulnerabilidade ao longo do tempo utilizando técnicas de análise espacial possibilitará que se avalie a eficácia dos esforços implementados.

Por fim, a estruturação de uma base de dados físicos e socioeconômicos e a descrição da variabilidade espacial das variáveis e índices propostos, classificados em graus de vulnerabilidade de acordo com os setores do GERCO/SC, poderá contribuir para o desenvolvimento de estudos futuros de diferentes áreas de conhecimento na escala do Estado de Santa Catarina.

Sob o ponto de vista econômico, a falta de uma efetiva gestão da zona costeira aliada ao seu uso e ocupação desordenados tornam necessárias e mais onerosas obras de ordem preventiva e/ou corretiva. Espera-se, com este trabalho, dar suporte a estudos de maior resolução, essenciais na implementação de medidas concretas de proteção da costa.

\section{Referências}

Abuodha P. A., Woodroffe C. D. 2010a. Vulnerability assessment. In: GREEN D. (ed.) Coastal zone management. Thomas Telford Limited, London, 262-290p

Abuodha P. A., Woodroffe, C. D. 2010b. Assessing vulnerability to sea-level rise using a coastal sensitivity index: a case study from southeast Australia. Journal of Coastal Conservation, 14:189-205.

Ayoade J. O. 1996. Introdução à climatologia para os trópicos. $4^{\mathrm{a}} \mathrm{ed}$. Bertrand Brasil, Rio de Janeiro, 332p.

Boak E. H., Turner, I. L. 2005. Shoreline definition and detection: a review. Journal of Coastal Research, 21(4):688-703.

Bonetti, J., Woodroffe, C. D. 2017. Spatial Analysis on GIS for Coastal Vulnerability Assessment. In: Bartlett, D. \& Celliers, L. (eds.). Geoinformatics for Marine and Coastal Management. Chapter 16. CRC Press, Boca Raton, p. 367-396. 
Bonetti J., Klein A. H. F., Muler, M., De Luca C. B., Silva G. V., Toldo Jr. E. E., Gonzalez, M. 2013. Spatial and numerical methodologies on coastal erosion and flooding risk assessment. In: FINKL C. (ed.) Coastal Hazards. Springer, Dordrecht, 423$442 \mathrm{p}$.

Bonetti, J.; Serafim, M. B.; Aboudha, P. \& Woodroffe, C. D. 2015. Multicriteria indices for coastal susceptibility assessment: a comparative study of embayed Brazilian and Australian coasts. In: CoastGIS 2015 - The 12th International Symposium for GIS and Computer Cartography for Coastal Zone Management. 2224 April 2015 Western Cape, South Africa. CSRI, Cape Town, p. 36-40.

Boruff, B. J., Emrich, C., Cutter, S. L. 2005. Erosion hazard vulnerability of US coastal counties. Journal of Coastal Research, 21(5): 932-943.

CEPAL - Comisión Económica para América Latina y el Caribe 2011. División de Desarrollo Sostenible y Asentamientos Humanos. Efectos del cambio climático en la costa de América Latina y el Caribe: dinámicas, tendências y variabilidad climática. Naciones Unidas, Santiago de Chile, 263p.

CEPAL - Comisión Económica para América Latina y el Caribe 2012. División de Desarrollo Sostenible y Asentamientos Humanos. Efectos del cambio climático en la costa de América Latina y el Caribe: efectos teóricos. Naciones Unidas, Santiago de Chile, 154p.

Crowell M., Leatherman S.P., Buckley M.K. 1991. Historical shoreline change: error analysis and mapping accuracy. Journal of Coastal Research, 7(3):839-852.

EURIMAGE 2001. Eurimage Products and Services: QUICKBIRD. Digital Globe, California, 10p.

FATMA - Fundação do Meio Ambiente 2010. Lista das espécies da fauna ameaçada de extinção em Santa Catarina: relatório técnico final. FATMA, Santa Catarina, $57 \mathrm{p}$.

FGDC-STD - Federal Geographic Data Committee 1998. Geospatial positioning accuracy standards (part 3): national standard for spatial data accuracy. Federal Geographic Data Committee, Washington, 25p

Freitas D. 2008. Quantificação de perigos costeiros e projeção de linhas de costa futuras para a Enseada do Itapocorói. Trabalho de conclusão de curso. Bacharelado em Oceanografia, Universidade do Vale do Itajaí, 61p.

Gornitz V. 1991. Global coastal hazards from future sea level rise. Palaeogeography, Palaeoclimatology, Palaeoecology, 89:379-398.

Gornitz V., White T.W., Cushman R.M. 1991. Vulnerability of the US to future sea level rise. In: Symposium on Coastal and Ocean Management, 7. Long Beach, Proceedings... Oak Ridge National Lab., Oak Ridge, 1345-1359p.

Gornitz V., White T. W. 1992. A coastal hazards database for the U.S. East Coast. ORNL/CDIAC-45, NDP-043A. Oak Ridge National Laboratory, Oak Ridge, 83p.

Hammar-Klose E. S., Thieler E. R. 2001. Coastal vulnerability to sea level rise: a preliminary database for the U.S. Atlantic, Pacific, and Gulf of Mexico Coasts. U.S. Geological Survey. Disponível em: http://pubs.usgs.gov/dds/dds68/. Acessado em: 4 de julho de 2015.

Hammar-Klose E. S., Pendleton E. A., Thieler E. R., Williams S. J. 2003. Coastal vulnerability assessment of Cape Cod National seashore to sea-level rise. Geological Survey. Disponível em: http://www.pubs.usgs.gov/of/2002/of02-233/caco.htm. Acessado em: 4 de julho de 2015 .

Hoefel, F. G. 1998. Morfodinâmica de praias arenosas oceânicas: uma revisão bibliográfica. Ed. da UNIVALI, Itajaí, 92p.

Horn Filho N.O., Diehl F.L. 2004. Santa Catarina coastal province, Brazil: geology, geomorphology and paleogeography. Journal of Coastal Research, SI39:311-315.

IBGE - Instituto Brasileiro de Geografia e Estatística 2000. Censo demográfico 2000: características da população e dos domicílios (resultados do universo). Disponível em: http://www.ibge.gov.br/home/estatistica/populacao/censo2000. Acessado em 1 de novembro de 2013.

IBGE - Instituto Brasileiro de Geografia e Estatística 2010a. Cidades@. Disponível em: http://www.cidades.ibge.gov.br/xtras/home.php. Acessado em 1 de novembro de 2013.
IBGE - Instituto Brasileiro de Geografia e Estatística 2010b. Censo Demográfico 2010: Famílias e domicílios (resultados da amostra). IBGE, Rio de Janeiro, 203p.

IBGE - Instituto Brasileiro de Geografia e Estatística 2011. Base de informações do Censo Demográfico 2010: resultados do Universo por setor censitário. IBGE, Rio de Janeiro, 201p.

IPCC - Intergovernmental Panel on Climate Change 2014. Climate Change 2014: Synthesis Report. Contribution of Working Groups I, II and III to the Fifth Assessment Report of the Intergovernmental Panel on Climate Change (Core Writing Team, R.K. Pachauri and L.A. Meyer [Eds.]). IPCC, Geneva, Switzerland

Klein, A. H. F., Short, A. D., Bonetti, J. 2016. Santa Catarina beach systems. In: Short, A. D., Klein, A. H. F. (eds.). Brazilian Beach Systems. Chapter 17. Coastal Research Library 17. Springer. Switzerland, p. 465-506.

Krueger J. 2011. Análise dos Parâmetros meteorológicos e oceanográficos dos eventos de ressaca, ocorridos entre 2001 e 2010, no Estado de Santa Catarina. Trabalho de conclusão de curso. Bacharelado em Oceanografia, Centro de ciências tecnológicas da Terra e do Mar, Universidade do Vale do Itajaí, $77 \mathrm{p}$.

Leatherman S. 2003. Shoreline change mapping and management along the U.S. East Coast. Journal of Coastal Research, SI38:5-3

Mazzer A. M. 2007. Proposta metodológica de análise de vulnerabilidade da orla marítima à erosão costeira: aplicação na costa sudeste da Ilha de Santa Catarina, Florianópolis-SC, Brasil. Tese de Doutorado. Pós-Graduação em Geociências, Universidade Federal do Rio Grande do Sul, 169p.

McLaughlin S., Cooper J. A. G. 2010. A multi-scale coastal vulnerability index: a tool for coastal managers? Environmental Hazards, 9:233-248.

McLaughlin S., Mckenna J., Cooper J. A. G. 2002. Socio-economic data in coastal vulnerability indices: constraints and opportunities. Journal of Coastal Research, Northern Ireland, SI36:487-497.

Monteiro M. A, Furtado S. M. A. 1995. O clima do trecho Florianópolis - Porto Alegre: uma abordagem dinâmica. Geosul, 20(19):117-133.

Muehe, D., Klumb-Oliveira, L. 2014. Deslocamento da linha de costa versus mobilidade praial. Quaternary and Environmental Geosciences, 5(2):121-124.

Muler M. 2012. Avaliação da vulnerabilidade de praias da Ilha de Santa Catarina a perigos costeiros através da aplicação de um índice multicritério. Dissertação de Mestrado. Pós-Graduação em Geografia, Departamento de Geociências, Universidade Federal de Santa Catarina, 184p

Muler, M. Bonetti J. 2014. An integrated approach to assess wave exposure in coastal areas for vulnerability analysis. Marine Geodesy, 37(2): 220-237.

Mussi C. S. 2011. Avaliação da sensibilidade ambiental costeira e de risco à elevação média dos oceanos e incidência de ondas de tempestade: um estudo de caso para a Ilha de Santa Catarina, SC. Dissertação de mestrado. Pós-graduação em Ciência e Tecnologia Ambiental, Universidade do Vale do Itajaí, 54p.

Nguyen, T. T. X. And Woodroffe, C. D. 2015. Assessing relative vulnerability to sea level rise in the western part of the Mekong River Delta in Vietnam. Sustainability Science, September 2015: $1-15$

Nguyen, T. T. X., Bonetti, J., Rogers, K., Woodroffe, C. D. 2016. Indicator-based assessment of climate-change impacts on coasts: a review of concepts, approaches and vulnerability indices. Ocean \& Coastal Management, 123:18-43.

Pavan R. A. 2012. Avaliação da sensibilidade ambiental costeira e de risco sócio ambiental do litoral centro-sul catarinense a eventos naturais extremos e à elevação do nível médio dos oceanos. Dissertação de mestrado. Pós-Graduação em Ciência e Tecnologia Ambiental, Centro de ciências tecnológicas da Terra e do Mar, Universidade do Vale do Itajaí, 80p.

Piana C. F. B., Machado A. A., Selau L. P. R. 2009. Estatística básica: versão preliminar. Universidade Federal de Pelotas, Pelotas. Disponível http://www.energiapura.net.br/alunos/planejamento_experimento s/Aulas_PAE/aula1_PAE/Apostila_EB.pdf. Acessado em 2 de janeiro de 2016.

Rodrigues M. L. G., Franco D., Sugahara S. 2004. Climatologia de 
frentes frias no litoral de Santa Catarina. Revista Brasileira de Geofísica. 22(2):135-151.

Rudorff F. M., Bonetti J. 2010. Avaliação da suscetibilidade à erosão costeira de praias da Ilha de Santa Catarina com base em geoindicadores e técnicas de análise espacial de dados. Brazilian Journal of Aquatic Science and Technology, 14:9-20.

Rudorff F. M., Bonetti J., Moreno D. A., Oliveira C. A. F., Murara P. G. 2014. Maré De Tempestade. In: Herrmann, M. L. P. (ed.) Atlas de Desastres Naturais do Estado de Santa Catarina: período de 1980 a 2010. $2^{\mathrm{a}}$ ed. IHGS, Florianópolis, 151-154p.

Santa Catarina 2006. Decreto $\mathrm{n}^{\mathrm{o}} 5.010$, de 22 de dezembro de 2006. Regulamenta a Lei n. 13.553, de 16 de novembro de 2005. Lex: coletânea de legislação e jurisprudência, Florianópolis.

Scolaro T. L. 2013. Avaliação da sensibilidade ambiental costeira e análise de risco socioambiental do litoral centro-norte catarinense, com base na vulnerabilidade do ambiente às mudanças climáticas. Dissertação de mestrado. Pós-Graduação em Geociências, Instituto de Geociências, Universidade Federal do Rio Grande do Sul, 129p.

Sharples C., Mount R. 2009. The Australian coastal smartline geomorphic and stability map version 1: manual and data directory. University of Tasmania, School of geography and environmental studies, $140 \mathrm{p}$.

Silva A. F. 2010. Comportamento morfodinâmico e sedimentar das praias adjacentes ao promontório de Itapirubá, SC, Brasil. Dissertação de Mestrado. Pós-graduação em Geografia, Departamento de Geociências, Universidade Federal de Santa Catarina, 131p.

Szlafsztein F., Sterr, A. 2007. A GIS-based vulnerability assessment of coastal natural hazards, state of Pará, Brazil. Journal of Coastal Research, 11(1): 53-66.

Thieler E.R., Himmelstoss E.A., Zichichi, J.L., Ergul, A. 2009. Digital Shoreline Analysis System (DSAS) version 4.0: an ArcGIS extension for calculating shoreline change. U.S. Geological Survey Open-file Report 2008-1278, 79p.

Torresan S., Critto A., Dalla Valle M., Harvey N., Marcomini A. 2008. Assessing coastal vulnerability to climate change: comparing segmentation at global and regional scales. Sustainability Science, 3:45-65.

Trucollo E.C. 1998. Maré meteorológica e forçantes atmosféricas locais em São Francisco do Sul - SC. Dissertação de Mestrado. Pós-Graduação em Engenharia Ambiental, Universidade Federal de Santa Catarina, 100p.

UNISDR - United Nations International Strategy for Disaster Reduction 2009. UNISDR Terminology on Disaster Reduction. United Nations, Geneva, Switzerland.

USACE - US Army Corps of Engineers 2002. Water Wave Mechanics. In: USACE. Coastal Engineering Manual. Vicksburg, Mississippi, $121 \mathrm{p}$.

Vieira Da Silva G., Muler M., Prado M. F. V., Short A. D., Klein A. H. F., Toldo Jr. E. E. 2016. Shoreline change analysis and insight into the sediment transport path along Santa Catarina Island north shore, Brazil. Journal of Coastal Research, 32(4): 863-874.

Zazula J. 2005. Find Polyline Angle. City of Barrie, Canada. Disponível em: http://arcscripts.esri.com/details.aspdbid=14234. Acessado em 1 de junho de 2013.

Recebido 20 de junho de 2016 Aceito 30 de outubro de 2017 